\title{
Vulnerability of the developing brain to hypoxic-ischemic damage: contribution of the cerebral vasculature to injury and repair?
}

\author{
Ana A. Baburamani ${ }^{1,2 *}$, C. Joakim Ek ${ }^{2}$, David W. Walker ${ }^{1,3}$ and Margie Castillo-Melendez ${ }^{1}$ \\ ${ }^{1}$ The Ritchie Centre, Monash Medical Centre, Monash Institute of Medical Research, Clayton, Melbourne, VIC, Australia \\ 2 Sahlgrenska Academy, Gothenburg University, Göteborg, Sweden \\ ${ }^{3}$ Department of Obstetrics and Gynaecology, Monash University, Clayton, Melbourne, VIC, Australia
}

\section{Edited by: \\ Antonio Colantuoni, Physiology at the International School for Advanced Studies (SISSA/ISAS), Italy}

Reviewed by:

Pasquale Pagliaro, Università di Torino, Italy

Giovanna Zoccoli, University of Bologna, Italy

*Correspondence:

Ana A. Baburamani, Perinatal Centre, Department of Physiology and Neuroscience, Sahlgrenska

Academy, Gothenburg University, Göteborg 40530, Sweden. e-mail:ana.baburamani@ neuro.gu.se
As clinicians attempt to understand the underlying reasons for the vulnerability of different regions of the developing brain to injury, it is apparent that little is known as to how hypoxia-ischemia may affect the cerebrovasculature in the developing infant. Most of the research investigating the pathogenesis of perinatal brain injury following hypoxia-ischemia has focused on excitotoxicity, oxidative stress and an inflammatory response, with the response of the developing cerebrovasculature receiving less attention. This is surprising as the presentation of devastating and permanent injury such as germinal matrix-intraventricular haemorrhage (GM-IVH) and perinatal stroke are of vascular origin, and the origin of periventricular leukomalacia (PVL) may also arise from poor perfusion of the white matter. This highlights that cerebrovasculature injury following hypoxia could primarily be responsible for the injury seen in the brain of many infants diagnosed with hypoxic-ischemic encephalopathy (HIE). Interestingly the highly dynamic nature of the cerebral blood vessels in the fetus, and the fluctuations of cerebral blood flow and metabolic demand that occur following hypoxia suggest that the response of blood vessels could explain both regional protection and vulnerability in the developing brain. However, research into how blood vessels respond following hypoxia-ischemia have mostly been conducted in adult models of ischemia or stroke, further highlighting the need to investigate how the developing cerebrovasculature responds and the possible contribution to perinatal brain injury following hypoxia. This review discusses the current concepts on the pathogenesis of perinatal brain injury, the development of the fetal cerebrovasculature and the blood brain barrier (BBB), and key mediators involved with the response of cerebral blood vessels to hypoxia.

Keywords: hypoxia, cerebral blood vessels, angiogenesis, hemorrhage, blood-brain barrier

\section{INTRODUCTION}

The most devastating permanent injury that can occur in the developing fetus is germinal matrix-intraventricular hemorrhage (GM-IVH) with the incidence greater in premature and low birth weight babies. Term infants are more susceptible to breakdown of the blood brain barrier (BBB), brain edema, subcortical hemorrhage and impaired metabolism (Wigglesworth and Pape, 1978; Van den Broeck et al., 2007). Volpe (1989) suggests that consequences and subsequent neuropathology that originate from GMIVH include destruction of the germinal matrix, periventricular hemorrhagic infarction (possibly of venous origin), periventricular leukomalacia (PVL), hydrocephalus and pontine neuronal necrosis. Analysis of neonates with PVL suggest that this area of infarct contained poorly perfused vessels of an irregular capillary shape, suggesting a relationship between vascular supply to this region and the pathology of PVL (Takashima and Tanaka, 1978a).

Clinicians have long sought to understand the inherent vulnerability of the sub-ependymal germinal matrix to hemorrhage and periventricular white matter to necrosis. Observations of infarctions in these periventricular areas were seen to occur in watershed vascular or border "end zones" (areas where long and penetrating arteries end). These areas were deemed more vulnerable to poor perfusion and less capable of tolerating fluctuations of cerebral blood flow and cerebral venous pressure especially following hypoxia-ischemia and/or reperfusion (De Reuck, 1971; Takashima and Tanaka, 1978a,b; Wigglesworth and Pape, 1978; Volpe, 1989).

Ballabh (2010) suggests that the germinal matrix, which is highly vascularized, may have an inherent fragility during development deeming it vulnerable to hemorrhage, which may be further exacerbated following hypoxia. Interestingly, Volpe (1989) also highlights that many thin walled cerebral blood vessels are the source of bleeding. This finding was also seen in the beagle puppy model of germinal matrix hemorrhage (Trommer et al., 1987; Ment et al., 1991) but not in the rhesus monkey (Lenn and Whitmore, 1985). The observation of thin walled blood 
vessels could be indicative of structural immaturity or ongoing angiogenesis. However, Back et al. consider that injury occurring in periventricular white matter is more likely to be due to cellular immaturity - especially of oligodendrocyte progenitors - than of the vascular elements within these regions (Back et al., 2007; McClure et al., 2008).

The response of the cerebrovasculature following hypoxiaischemia and how this may contribute to perinatal brain injury is not well investigated. In the adult brain, robust up-regulation of vascular endothelial growth factor (VEGF) occurs following cerebral hypoxia and/or ischemia which, as an adaptive response, results in the formation of new blood vessels. However, newlyformed blood vessels are fragile and prone to rupture. The observation of thin walled blood vessels in regions prone to bleeding and hemorrhage (Volpe, 1989), could be indicative of structural immaturity or ongoing angiogenesis. Incomplete development of hypoxia-induced angiogenesis could be a major factor in the cerebral injury that follows the birth of a severely hypoxic fetus, or which arises in the neonate where resuscitation is difficult and prolonged. The response of blood vessels, changes in blood flow, and the reactive expression of proteins by the vasculature could be directly affected by the processes of excitotoxicity and oxidative stress which are already known to be closely inter-related, and the occurrence of hemorrhage and leukomalacia highlight that the response of the vasculature is pivotal. Understanding the development and response of the cerebrovasculature and BBB could reveal reasons for regional vulnerability of the immature brain to vascular damage.

\section{PERINATAL HYPOXIA}

Intrapartum asphyxia is present in up to 25 per 1000 live births in term deliveries (Low, 2004). However, the incidence of antepartum and/or intrauterine asphyxia is much more difficult to determine. Post mortem studies indicate that hypoxic-ischemic and asphyxic episodes that occur during pregnancy significantly contribute to brain injury, morbidity and mortality (Sims et al., 1985; Low et al., 1989; Low, 2004). Intrauterine asphyxia also contributes to cognitive impairment, developmental delay, epilepsy, motor deficits and cerebral palsy (Low et al., 1989; Cowan et al., 2003; Low, 2004; Glass et al., 2009). The Australian Cerebral Palsy Foundation states that the incidence of cerebral palsy (approximately 1 in 400 live births) has remained relatively unchanged over the last 40 years, despite reduction in the rate of perinatal morbidity (Stanley and Watson, 1992). This highlights the importance of understanding the contribution of intrauterine events, such as fetal hypoxia, academia, and asphyxia to the pathogenesis of brain injury.

Asphyxia describes an insufficiency to exchange respiratory gases (Stephens, 1995; Parer, 1998). The severity of asphyxia and hypoxia-ischemia are thereby defined as a series of cardio-respiratory changes, including hypoxia (decreased pO2), hypercapnia (increased pCO2), hypoxemia, metabolic acidosis (increased lactate), impaired blood gas exchange and ischemia decreased oxygen delivery to tissue. Some argument exists over whether "asphyxia" can be applied to events occurring during gestation since, in the adult, asphyxia describes deficient oxygen supply arising from the inability to breathe (such as seen during strangulation). In utero the fetus does not breathe, but fetal asphyxia does arise from insufficient umbilical or uterine blood flow resulting in impaired blood gas exchange (Parer, 1998; Low, 2004), and is therefore, used to describe the simultaneous decrease in oxygen and increase in carbon dioxide levels in fetal blood and tissues. However, without measurement of blood gases and cardiovascular parameters, the definition of asphyxia is difficult, and in this review of fetal and neonatal pathophysiology the terms hypoxia or hypoxia-ischemia will be used. Common causes of hypercapnic hypoxia in the fetus include maternal infection, hypertension, diabetes and placental insufficiency, all of which have the tendency to reduce uterine and/or umbilical blood flows. Fetal factors can range from multiple births, tangling or obstruction of the umbilical cord, or partial separation of the placenta from the uterine wall. The extent of injury that can occur as a consequence of hypoxia are dependent on the duration, degree and frequency of the insult. The gestational age at which hypoxia occurs also affects the brain regions involved.

\section{PERINATAL BRAIN INJURY}

Hypoxia is one of the most common causes of neonatal brain injury, and it still remains to be well understood as to why some brain regions are more vulnerable to injury than others. The brain regions susceptible to hypoxic injury also change as the infant matures (Barkovich, 2005). A possible explanation for the correlation between gestational age and the type of brain injury may be the changing location of intervascular "watershed" boundary zones. From human infant autopsy tissue it was found the most prominent injury that occurred was hemorrhage with areas of necrotic tissue, and with exacerbated injury in neonates that had suffered hypoxia-ischemia or a complicated pregnancy. A recent study demonstrated that hypoxic-ischemic injury in term infants resulted in subcortical hemorrhage in $13 \%$ of the subjects, while $24 \%$ of preterm infants showed IVH (Van den Broeck et al., 2007). From studies in fetal sheep it has been shown that younger fetuses can tolerate longer periods of complete cessation of umbilical blood flow, up to $25 \mathrm{~min}$, however, near-term fetuses can only withstand up to $10 \mathrm{~min}$ (Mallard et al., 1994; Keunen et al., 1997). The differing tolerance across gestation to duration is suggested to be due to the greater tissue metabolic rate of the near term fetus, and hence the greater response in terms of excitotoxicity, free radical production, and propensity of mitochondrial damage (Bennet et al., 1999). To understand the impact hypoxia has on the developing brain, the most prominent types of brain injury are described below.

\section{Preterm brain injury}

Premature neonates who are also of a low birth weight are at the highest risk of PVL and GM-IVH. The source of GM-IVH was classified by Takashima and Tanaka (1978b), Wigglesworth and Pape (1978), and Volpe (1989) who described bleeding occurring around the subependymal germinal matrix (around the lateral ventricle) extending into the white matter. PVL is characterized by hemorrhagic necrosis of the white matter surrounding the lateral ventricles. It can be diffuse or focal and commonly occurs in the preterm infant [reviewed by Volpe (1998)]. Cellular immaturity of oligodendrocytes also significantly contributes to regional 
vulnerability of white matter (Alvarez-Diaz et al., 2007; Back et al., 2007). This "selective vulnerability" governs the subsequent manifestation of injury. Blood vessels within the germinal matrix are fragile, particularly during the period of high cell turnover (24-32 weeks gestation) associated with corticogenesis. At this point of gestation, the oxygen and nutrient demand of the germinal matrix is high, and the requirement for correspondingly high blood flow appears to be met by a network of very fragile and leaky blood vessels. GM-IVH is a common brain injury in premature infants, particularly at $<30$ weeks gestation, and is more common when babies suffer additional stresses such as respiratory distress syndrome, pneumothorax, or high blood pressure, although it can also occur in healthy premature and full-term babies. IVH implies structural immaturity of blood vessels in the germinal matrix, and is associated with deficient autoregulatory capacity and pressure-passive cerebral perfusion (Pryds et al., 1989). Elevation of intracerebral venous pressure may be involved, as obstructed venous drainage has been shown to be associated with periventricular hemorrhage (Perlman, 1998).

The developmental status of the cerebral vasculature is also thought to be a critical predisposing factor in the pathogenesis on PVL. The topographic predilection of white matter injury is distinct between immature and mature brains, because regional cerebral blood flow and metabolic demand are rapidly changing during the perinatal period. In the immature brain, the end-zones of perforating arteries through the cerebral cortex are located in the periventricular white matter, which is a watershed area vulnerable to PVL. A predisposing factor in the pathogenesis of IVH in preterm infants is the microvascular architecture of the germinal matrix, which is at the end zone of thalamo-striatal arteries and in the venule structure zone of the ventricular side of terminal vein (Takashima et al., 1978). Hypotension or hypoxemia may induce focal hypoxic-ischemic changes in the arterial end zone within the germinal matrix, and with reperfusion or overperfusion following hypoxia-ischemia, venous hemorrhage may occur due to the paucity of supportive connective tissue (Kamei et al., 1992). In addition, the microvasculature of the germinal matrix is frail because of an abundance of angiogenic blood vessels (Ballabh et al., 2007) that possess few pericytes, an incomplete and immature basal lamina, and an investment of astrocytic processes ("end-feet") with a deficiency of glial fibrillary acidic protein (GFAP) (El-Khoury et al., 2006). Pericyte coverage is less in the germinal matrix vascular bed than in cortical gray or white matter in human fetuses, premature infants (20-28 weeks gestation) and premature rabbit pups (Braun et al., 2007), consistent with their propensity for structural collapse and hemorrhage.

\section{Term brain injury}

Term neonates who undergo birth asphyxia or hypoxia-ischemia late in gestation tend to have injury in the deep gray matter, hippocampus, brainstem, and thalamic regions (Swarte et al., 2009). The most common injuries are parasagittal cerebral injury, and injuries to the basal ganglia, including thalamic bleeding with associated IVH (Van den Broeck et al., 2007). In recent years mild white matter injury has also been reported to occur in the term neonate, occurring near birth (Li et al., 2009; Swarte et al., 2009). Cowan et al. (2003) studied MRI and post mortem tissue of full term infants and found that the period immediately preceding birth was an important time when brain injury could arise. The vascular boundary zones in term infants lies between the anterior and middle cerebral arteries and between the middle and the posterior cerebral arteries. PVL and hemorrhage tend to occur in term neonates at a lower but still significant incidence (Wigglesworth and Pape, 1978; Inder and Volpe, 2000; Perlman, 2004; Takenouchi et al., 2012). Watershed injury can also occur with or without deep cortical involvement (Swarte et al., 2009).

\section{Perinatal stroke}

Perinatal stroke is defined as a cerebrovascular event that can occur between 28 weeks gestation and 28 days postnatal age. The incidence of perinatal stroke (thromboembolism) is approximately 1 in 4000 live births, with $<5 \%$ also being associated with asphyxia (Estan and Hope, 1997; Lynch et al., 2002). Clinical studies from full term neonates that have experienced perinatal arterial stroke show a greater incidence of cerebral palsy, epilepsy, language delay, behavioral abnormalities, and brain injury to the basal ganglia, internal capsule Broca's and Wernicke's area. Increased stroke size also further increases the incidence of cerebral palsy (Lee et al., 2005).

Clinical manifestation of infants who have experienced stroke include seizure activity and apnea from the second postnatal day (Koelfen et al., 1995; Perlman, 2004), this can also persist to neonatal encephalopathy (Ramaswamy et al., 2004). Focal stroke in the term infant is most common with the presentation of seizure activity without associated encephalopathy. However, if neonatal encephalopathy also occurred, neurodevelopmental outcome significantly worsened (de Vries et al., 1997; Perlman, 2004; Ramaswamy et al., 2004).

\section{PATHOPHYSIOLOGY OF HYPOXIA-ISCHEMIA IN THE NEONATAL BRAIN}

The developing brains' response to global hypoxia-ischemia is a multi-step process. Within the first few hours, regionally-specific increases of cerebral blood flow occur, followed by decreases due to either regional vasoconstriction or the progressive collapse of cardiac output, with the subsequent onset of excitotoxicity, energy depletion and generation of free radicals collectively resulting in increased apoptotic and necrotic cell death, and edema formation (Wigglesworth and Pape, 1978; Bennet et al., 1998; Jensen et al., 1999; Shalak and Perlman, 2004; Ferrari et al., 2010a). A secondary phase of injury occurs in the following hours and days, resulting in a neuroinflammatory response, mitochondrial permeabilisation, reperfusion, and a loss of cerebral autoregulation which can also lead to increased free radical production (Inder and Volpe, 2000; Hamrick and Ferriero, 2003; McLean and Ferriero, 2004; Hagberg et al., 2009; Leonardo and Pennypacker, 2009). More recently it has been described that a tertiary phase of brain injury, occurring in the weeks to years following an insult, may also contribute to exacerbating injury and/or preventing repair when mechanisms such as an inflammatory response persist (Fleiss and Gressens, 2012).

\section{CNS excitotoxicity}

Excitotoxicity refers to cell death that occurs due to intracellular accumulation of calcium resulting from the prolonged opening 
of voltage-sensitive channels associated with excitatory amino acid receptors (Beal, 1992). Prolonged neuronal depolarization increases neurotransmitter release, but astrocytic re-uptake of glutamate becomes restricted due to low availability of ATP, so overstimulation of glutamate receptors occurs due to the presence of excess extracellular glutamate (McLean and Ferriero, 2004) leading, in some cases, to seizure activity (Jensen et al., 1998; Bennet et al., 2010). Glutamate and adenosine, whose receptors are expressed on excitatory neurons, are both implicated in excitatory mediated injury following hypoxia (McLean and Ferriero, 2004). In addition, neurons are vulnerable to hypoxia-induced injury due to their high dependence on oxygen. Neuronal glutamate release, re-uptake and resynthesis is a tightly regulated metabolic pathway that is closely coupled with cerebral glucose oxidation demand. Glutamate receptors are highly expressed during fetal and neonatal development, so any severe fluctuations, such as those resulting from hypoxia can have devastating consequences (Low, 2004; McLean and Ferriero, 2004).

\section{Oxidative stress}

Oxidative stress arises when reactive oxygen species (ROS) and/or reactive nitrative species (RNS) are generated at a rate that exceeds the capacity of the endogenous antioxidant systems to neutralize them. The developing brain is considered to be extremely vulnerable to free radical damage due to its high lipid content (O'Brien and Sampson, 1965), with the amount of polyunsaturated fatty acids increasing during gestation, relatively high oxygen consumption and therefore, a high capacity to generate ROS, and low concentrations and activity of the principal antioxidant enzymes (Mishra and Delivoria-Papadopoulos, 1999; McLean and Ferriero, 2004; Vannucci and Hagberg, 2004; Ikonomidou and Kaindl, 2011; Miller et al., 2012). During normal metabolism ROS are produced in low concentrations, and may act as signaling molecules to modulate vasodilatation and cerebral blood flow (Paravicini et al., 2004), but under conditions that result in tissue hypoxia the accumulation of ROS can trigger the mitochondrial release of pro-apoptotic proteins resulting in cell death (Morita-Fujimura et al., 2001). Whether ROS-mediated damage occurs specifically to vascular elements in the developing brain is unclear.

$\mathrm{NO}$ is a weak free radical, produced by the actions of nitric oxide synthase (NOS) isoforms, and has a number of physiological roles including the physiological modulation of cerebral blood flow, modulating cellular respiration and mitochondrial ROS production, as well as having antioxidant properties (Beltran et al., 2000; Li and Jackson, 2002). Three well known isoforms of NOS-neuronal NOS (nNOS), endothelial NOS (eNOS), and inducible NOS (iNOS). iNOS is principally produced in macrophages, microglia, endothelial cells, and astrocytes, nNOS in neurons and eNOS primarily in endothelial cells and following neonatal hypoxia-ischemia has been found in neurons (Ferriero et al., 1996; McLean and Ferriero, 2004; Kaur and Ling, 2009).

Following neonatal hypoxia-ischemia both nNOS and eNOS are up-regulated (Van den Tweel et al., 2005). Whilst nNOS knockout mice appear to be protected following neonatal hypoxia-ischemia (Ferriero et al., 1996), studies from eNOS knockout mice suggest eNOS may play a protective role hypoxia-ischemia in the adult brain (Huang et al., 1996), which may be due to eNOS influencing neural migration and outgrowth and acting as a downstream regulator of angiogenesis (Chen et al., 2005). The lipid peroxidation that occurs following acute hypoxia in the fetal brain (Ikeda et al., 1998; Castillo-Melendez et al., 2004) may be due to the generation of peroxynitrite (OONO), following the non-enzymatic combination of $\mathrm{NO}$ and superoxide (Tan et al., 1998). Lipid peroxidation affects immature oligodendrocytes in particular in the preterm fetal brain (Back et al., 1998), and may be a major factor in the white matter damage that can arise from hypoxic insult in the developing brain (Back et al., 1998; Baud et al., 2004).

\section{Response of inflammatory cells}

Cell death that is mediated by a neuroinflammatory response is complex. Resident microglia are some of the first cells to become "activated." Amoeboid microglial cells, important for phagocytosis in the developing brain, are found in clusters in periventricular white matter and in close association with blood vessels in many brain regions (Fujimoto et al., 1989; Kaur et al., 2007). Microglia are the resident immune cells in the nervous system, whose presence is also related to vascularization, particularly in the early developmental stages of the human brain (Fujimoto et al., 1989). Microglia are also associated with active myelination during development (Hutchins et al., 1992; Ling and Wong, 1993; Kaur et al., 2007; Kaur and Ling, 2009). Activated microglia and astrocytes migrate to ischemically damaged regions of the brain and attempt to clean up cellular debris (Leonardo and Pennypacker, 2009). Following hypoxia-ischemia, compromise of the BBB (section "Compromise of the Blood Brain Barrier") allows the entry of macrophages and cytokines into the circulation (Alvarez-Diaz et al., 2007; Leonardo and Pennypacker, 2009). Activated microglia are known to produce inflammatory cytokines interleukin-1 $\beta$ (IL-1 $\beta$ ), IL-6 and tumor necrosis factor$\alpha$ (TNF- $\alpha$ ), as well as ROS, and RNS (Kaur and Ling, 2009). Circulating cytokines, which may gain increased entry into the brain through the compromised BBB, may then exacerbate excitotoxicity by again stimulating glutamate release, and free radical and NO production (McLean and Ferriero, 2004).

\section{CEREBROVASCULAR DEVELOPMENT IN THE FETUS}

Vascularization of the brain begins during embryogenesis, continues into the newborn period, and involves a tightly regulated process of vasculogenesis followed by angiogenesis (Mito et al., 1991; Breier et al., 1992; Ballabh et al., 2004a), when endothelial cells differentiate and proliferate into avascular tissue (Yancopoulos et al., 2000). In the human embryo intra-cerebral blood vessels appear from 7 weeks gestation when the basement membrane of the capillary network forms (Korzhevskii and Otellin, 2000). Newly developed blood vessels are initially large (relatively), irregular in shape, and permeable to hydrophilic substances (Stonestreet et al., 1996), but become thinner and uniformly shaped as the endothelial cells become more tightly interconnected (Engelhardt, 2003).

The germinal matrix, which is abundant with angiogenic vessels (Ballabh et al., 2007; Ballabh, 2010), is the source of neuroblasts from $\sim 10$ weeks gestation and glioblasts (oligodendrocyte 
and astrocyte precursors) in the 3rd trimester (Wigglesworth and Pape, 1978; Volpe, 1989). Heubner's artery is the main vascular channel providing nutrients to this progenitor zone surrounding the lateral ventricle. The germinal matrix is also a terminal area for the medullary artery which extends through to deep white matter (Takashima and Tanaka, 1978b; Wigglesworth and Pape, 1978; Volpe, 1989). By 36 weeks gestation the germinal matrix is nearly involuted when, at this time, cortical regions are undergoing vascular development (Wigglesworth and Pape, 1978; Volpe, 1989). The processes involved in this involution are not well understood, but could be determinants of the increased susceptibility of the germinal matrix to rupture at this time.

The caudate and thalamus develop a distinctive network of fine, circular capillaries in comparison to white matter and subependymal regions, where vessels run perpendicular to the ventricle and have an elliptical shape (Takashima and Tanaka, 1978b). The vascular density of tissue is closely correlated with metabolic demand and hence, cerebral blood flow (Miyawaki et al., 1998), and as gestation proceeds so does vascular density, increasing in the putamen, germinal matrix, and cortex. There are some conflicting findings about the vascularization of the white matter, where Mito et al. (1991) found no change of vascular density during gestation, while others suggest an increase across gestation, (Gould and Howard, 1988; Mito et al., 1991; Miyawaki et al., 1998; Ballabh et al., 2004a), although the change is smaller and the blood vessel density is lower compared to other brain regions.

\section{ENDOTHELIAL PRECURSOR CELLS IN THE FETUS}

Lineage-committed angioblasts, termed endothelial progenitor cells (EPCs), migrate and congregate into clusters, called blood islands, forming the primary vascular plexus from which a complex microcirculation arises (Risau, 1997). In early embryogenesis, the vascular system develops essentially by vasculogenesis, in which angioblasts differentiate into endothelial cells to form a primitive capillary network, whereas angiogenesis - the sprouting of capillaries from preexisting blood vessels-begins later in embryogenesis and continues throughout fetal life (Risau et al., 1988). EPCs were originally identified as a population of stem cells in human peripheral blood and characterized by the expression of $\mathrm{CD} 34$, kinase insert domain receptor (KDR), and CD133 markers (Asahara et al., 1997; Peichev et al., 2000). Subsequently, EPCs have been isolated from bone marrow, fetal liver, and umbilical cord blood. Circulating EPCs are present during the 2nd trimester (Gussin et al., 2002) and seen to increase during gestational age (Sugawara et al., 2005) in pregnant women. Importantly, EPCs are also present in cord blood at various stages of gestation, increasing from low levels at 24-28 weeks to higher levels at 33-36 weeks gestation, equivalent to that found in term infants (Javed et al., 2008). Another study investigating circulating EPCs in preterm infants with bronchopulmonary dysplasia also showed that EPC levels were low at $<32$ weeks and increased during gestation, and extremely preterm infants with low levels of EPCs had an increased risk of developing bronchopulmonary dysplasia (Borghesi et al., 2009).

\section{ANGIOGENESIS}

Angiogenesis is the process of local proliferation, migration, and remodeling of pre-existing endothelial cells to form new blood vessels, whilst vascular remodeling occurs when an existing vascular network is modified by pruning and vessel enlargement forming interconnecting branches (Yancopoulos et al., 2000; Carmeliet, 2003). Initiation of angiogenesis occurs by the extensive interplay between a variety of cells and numerous growth factors. These include fibroblast growth factor (FGF; both acidic and basic), VEGF, platelet derived growth factor (PDGF), transforming growth factor (TGF) and the angiopoietins (angpt) (Tomanek and Schatteman, 2000). Mitogens, such as VEGF, are activated to enhance endothelial cell migration and proliferation. Endothelial cells migrate along newly deposited extracellular matrix tracts and form vessel sprouts, a process that requires extracellular matrix dissolution facilitated by the presence of proteases such as matrix metalloproteinase (MMP). Finally, tube and basement membrane formation occur triggering further processes which involve the recruitment of pericytes by endothelial cells, and the eventual formation of a "mature" blood vessel (Tomanek and Schatteman, 2000). In the brain, astrocytes induce endothelial cell and pericyte differentiation, but pericytes appear to migrate and cover capillary-like structures faster than astrocytes, which provide the end-feet that eventually invest the outer wall of the blood vessel (Ramsauer et al., 2002). Interestingly, hypoxia is a key regulator of angiogenesis and affects the expression of key angiogenic proteins.

\section{Vascular endothelial growth factor and receptors}

VEGF, first described as vascular permeability factor (VPF) (Keck et al., 1989; Leung et al., 1989), is a key regulator of vasculogenesis and angiogenesis (Breier et al., 1992; Breier and Risau, 1996). During angiogenesis, endothelial cells that express VEGF also produce plasminogen activators and MMPs to initiate extracellular matrix degradation, the first step in angiogenesis as described above. Subsequently, VEGF has an important role in stimulating the proliferation of endothelial cells (Breier et al., 1992). See Figure 1 for a summary.

VEGF has six homologous family members-VEGF-A (previously referred to as VPF, and also referred to as VEGF), placental growth factor (PIGF), VEGF-B, VEGF-C, VEGF-D, and VEGF-E. Three high-affinity tyrosine kinase receptors also exist-VEGFR1 (Flt-1), VEGFR-2 (fetal liver kinase (Flk-1) in the mouse/KDR in the human) and VEGFR-3 (Flt-4), and are highly expressed on endothelial cells (Breier et al., 1992; Breier, 2000; Carmeliet and Storkebaum, 2002). VEGF-A is the most active, through binding to VEGFR-1 and VEGFR-2 it is involved in blood vessel growth, endothelial cell mitogenesis, vasodilatation (via NO dependent pathways) and vascular permeability (Leung et al., 1989; Breier et al., 1992; Breier, 2000; Dimberg et al., 2010). VEGF-A has seven known isoforms; 121, 145, 148, 165, 183, 189, and 206 (Dvorak et al., 1995; Hoeben et al., 2004). It is the most widely studied of the VEGF family, and in this review article (to keep consistent with the studies referenced), the use of VEGF refers to VEGF-A, unless otherwise stated.

During embryogenesis, the formation of new blood vessels is largely guided by the actions of VEGF through binding with 


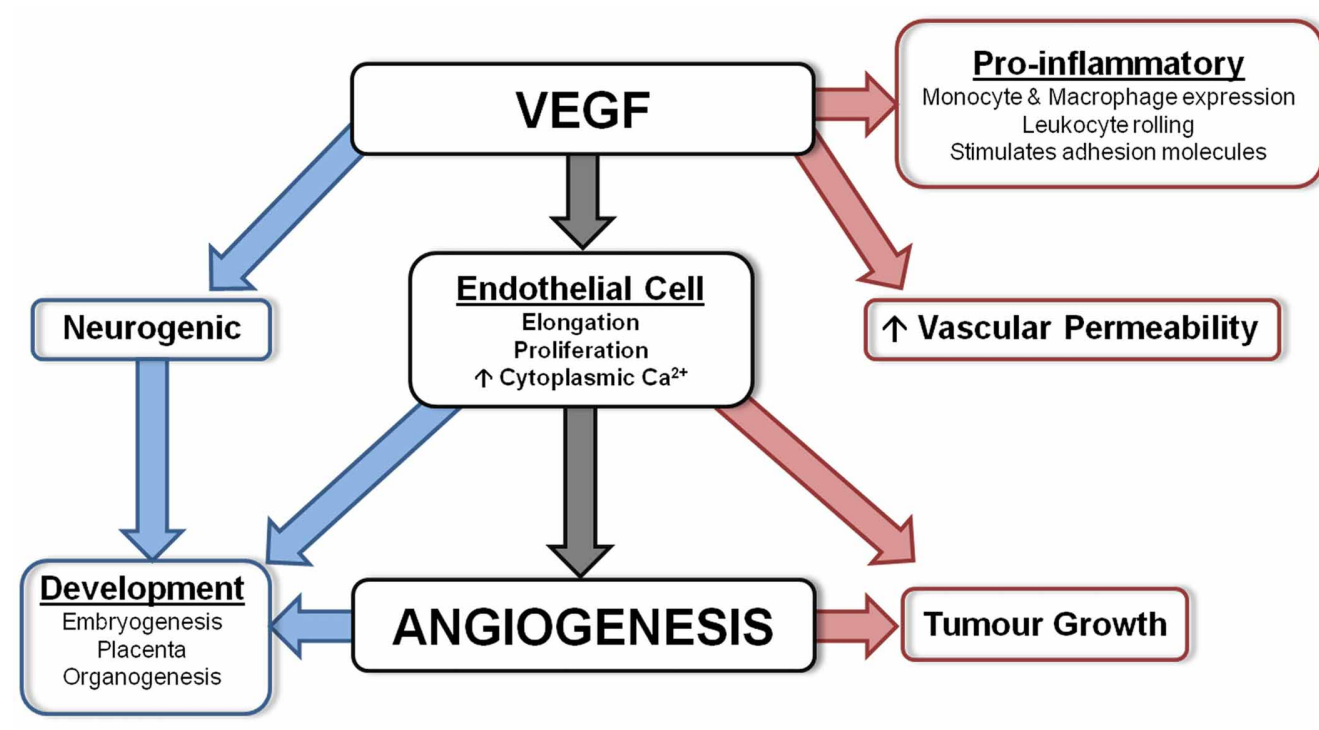

FIGURE 1 | Diagram summarizing the actions of VEGF. VEGF is involved in numerous important physiological processes. Angiogenesis is the main function of VEGF, however, it also has protective actions (shown in blue) which include neurogenesis and involvement during development, and detrimental actions (shown in red) including being a pro-inflammatory mediator, vascular permeability factor and involved in tumor growth.
VEGFR-2-responsible for both vascular and neuronal development (Carmeliet, 2003). VEGF and VEGFR-2 activation is also important for promoting neuronal growth, migration, maturation, and survival, and for axonal and dendritic outgrowth (Hermann and Zechariah, 2009; Sentilhes et al., 2010). VEGF is expressed by the embryonic neuroectoderm, the epithelium of the stem cell and progenitor regions of the brain. It has been suggested that during development VEGFR-1 may act as a decoy receptor, but it is a functionally important receptor isoform in the adult, as shown by the effects of hypoxia on the adult rodent cerebral vasculature (Marti and Risau, 1998). VEGF-B and VEGF-C isoforms are present in the brain early in embryonic life (Lagercrantz et al., 1998) and VEGF-C, through binding with VEGFR-3, has recently been shown to be important in the E15.5-18.5 mouse by stimulating growth of non-vascular progenitor cells, such as oligodendrocyte progenitors in the optic nerve (Alonso et al., 2011).

In the developing brain, the temporal and spatial expression of VEGF is correlated closely with vascularization and endothelial cell growth (Breier et al., 1992), and high expression by many cell types (neuroblasts, neuroepithelial, radial glia, astrocytes, pericytes, and endothelial cells) may be a signal coinciding with increasing neuronal metabolism that initiates angiogenesis (Virgintino et al., 2003; Rosenstein and Krum, 2004; Sentilhes et al., 2010). Increased glial VEGF expression occurs as stabilization of the cerebrovasculature is reached, when glial end-feet ensheath blood vessels (Ogunshola et al., 2000).

From 9 weeks gestation, VEGF is strongly expressed in the developing human telencephalon (Virgintino et al., 2003), and from 14 weeks there is strong expression of VEGF and VEGFR2 by neurons, glia, and blood vessels throughout the brain and cerebellum. During 21-34 weeks gestation VEGF is also strongly expressed in the cortex and white matter (Arai et al., 1998), and by
34 weeks neurons, astrocytes, and endothelial cells weakly express VEGF (Sentilhes et al., 2010). Figure 1 summarizes the numerous suggested physiological actions of VEGF.

\section{Angiopoietins}

Working in close conjunction with VEGF are the angpt and their ligand receptors Tie $(-1$ and -2$)$, part of the tyrosine receptor kinases. There are four members of the angpt family, with angpt1 and angpt-2 the most fully characterized (Yancopoulos et al., 2000; Carmeliet, 2003; Otrock et al., 2007; Hansen et al., 2008). Apart from the known significance of angpt-1 and angpt-2 in tumor growth, in the brain angpt-1 is important for stimulating vessel growth and branching, and is expressed by endothelial cells, astrocytes, and pericytes (Yancopoulos et al., 2000; Carmeliet, 2003; Kim et al., 2008). Angpt-1 knockout mice develop a normal vasculature but are incapable of adequate vascular remodeling. In contrast, angpt-1 over-expression leads to a functional vasculature, but with limited permeability (Suri et al., 1996; Thurston et al., 1999; Yancopoulos et al., 2000), suggesting that angpt-1 may be important for inhibiting vascular permeability.

Angpt-1 also has anti-inflammatory effects, particularly in limiting inflammation-induced vascular leakage and inhibiting neuronal apoptosis (Thurston et al., 1999, 2000; Valable et al., 2003; Hansen et al., 2008). Increased expression of angpt-1 promotes the "tightening" of vessels by increasing expression of tight junction proteins and decreasing permeability and plasma leakage (Thurston et al., 1999, 2000; Valable et al., 2005). Angpt-1 is also implicated in promoting endothelial cell survival, migration, and enhancing the interaction between endothelial cells and neighboring cells that result in the recruitment of pericytes (Suri et al., 1996).

Angpt-2, important in initiating vascular remodeling, has both agonist and antagonist actions to angpt-1 when binding 
to Tie-2, and co-expression with VEGF may dictate the function of angpt-2, determining whether vessel remodeling, vessel regression occurs (Maisonpierre et al., 1997; Beck et al., 2000; Yancopoulos et al., 2000; Gale et al., 2002). Over-expression of angpt-2 can lead to defective vascular remodeling, as for the angpt-1 knockout mouse (Maisonpierre et al., 1997), and high angpt-2 expression in the absence of VEGF can result in vessel regression, as seen following hypoxia and in tumor growth (Holash et al., 1999; Beck et al., 2000). Expressed mostly by endothelial cells, angpt-2 has been seen to degrade the extracellular matrix and disrupt junctions between endothelial cells in tumor vessels (Gale et al., 2002; Carmeliet, 2003). In the adult mouse brain the presence of angpt- 2 and VEGF resulted in increased microvascular density, increased MMP-9 and decreased zona occludin ( $\mathrm{ZO}$ ) expression, leading to increased BBB permeability (Zhu et al., 2005).

\section{THE BASEMENT MEMBRANE}

The basement membrane (also commonly referred to as the basal lamina) exists between endothelial cells and astrocytes (del Zoppo and Mabuchi, 2003). In the brain, it is functionally important in restricting extravasation of protein rich fluids and blood components into the parenchyma (Hamann et al., 1996; Scholler et al., 2007). The basement membrane is composed of collagens and non-collagen glycoproteins (including laminin, and fibrinogen), glycosamineglycans and proteoglycans (heparin sulphate). A direct consequence of the binding of collagen IV and laminin is the tissue support it provides the basement membrane (Charonis et al., 1985; Yurchenco and Schittny, 1990; Hamann et al., 1995; Lukes et al., 1999; Jakobsson et al., 2008). Ment et al. (1991) suggested that basement membrane proteins (laminin and collagen IV) are important in providing structural integrity to blood vessels, particularly in the germinal matrix (subventricular zone) to prevent rupture. Changes in expression are also seen to occur following ischemia (section "Degradation of Basal Lamina").

Laminin is a non-collagenous constituent of the basement membrane and during development its presence is closely related to the functional and structural maturation of blood vessels (Timpl et al., 1979; Risau and Lemmon, 1988). Laminin is made up of a family of heterotrimeric glycoproteins containing one of $5 \alpha, 3 \beta$, or $3 \gamma$ chains, with $\alpha$-chains being highly bioactive and important in vascular development (Veltkamp et al., 2006; Jakobsson et al., 2008). Normally, laminin expression is confined to the basement membrane, but during development laminin expression is also present in endothelial cells and neuronal and glial precursors, and reactive astrocytes in response to injury (Liesi et al., 1984; Liesi, 1985; Wagner et al., 1997). Angiogenesis is associated with up-regulation of laminin expression and signaling (Risau and Lemmon, 1988; Milner and Campbell, 2002). Regional and time-related variations of expression of the $\alpha 1, \alpha 4$, and $\alpha 5$ isoforms in germinal matrix, gray and white matter of both human tissue and rabbit pups may reflect different rates of local angiogenesis (Xu et al., 2008).

Collagen IV is derived from a triple helical molecule, [ $\alpha 1$ (IV), 2a2(IV)] (Sanes et al., 1990; Yurchenco and Schittny, 1990; Ment et al., 1991) and plays a fundamental role in the maintenance of integrity and function of blood vessels, particularly when there is increased metabolic demand (Poschl et al., 2004). Studies from knockout mice suggest collagen IV is not important until embryonic day 10, while other studies indicate it is important earlier in development, possibly influencing neurite outgrowth (Laurie et al., 1980; Poschl et al., 2004).

Fibronectin is expressed highly during developmental angiogenesis and is essential during embryogenesis (George et al., 1993). Fibronectins are a family of glycoproteins, and important constituents of the basement membrane, promoting endothelial cell adhesion, migration, and organization of the cytoskeleton (Wang and Milner, 2006).

\section{THE BLOOD-BRAIN BARRIER}

The cerebral vascular system has anatomical and physiological barriers that regulate the transfer of compounds into the brain. The major functions of the $\mathrm{BBB}$ include protection of the brain from the chemical environment of blood, selective transport of substances into and out of the brain, and metabolism of blood and brain substances (Risau and Wolburg, 1990). The structure of the $\mathrm{BBB}$ is composed of capillary endothelial cells, tight junctions, astrocytes, pericytes, and the basement membrane, collectively referred to as the neurovascular unit (Saunders et al., 2008; Abbott et al., 2010). The anatomical barrier lies in the tight junctions that exist between endothelial cells (Brightman and Reese, 1969) that transform into a continuous cellular layer which is specialized to protect the brain. Surrounding the endothelial cells is a basement membrane, pericytes and the astrocytic end-feet that also contribute to barrier function (see below). To complement the cerebrovascular barrier, is a barrier at the epithelial level of the choroid plexus that constitutes the blood-cerebrospinal fluid (CSF) barrier with many similar functions to the BBB. The barrier forming cells at both these barriers also encompass a number of enzymatic systems such as the cytochrome-P450/phase II enzymes, complemented by efflux transporters, which inactivates and reduce the entry of potentially neurotoxic compounds into the brain (Ek et al., 2012). At the same time, nutrients necessary for brain function such as amino acids and glucose are actively transported into the brain.

Barrier properties seem to be established in cerebral vessels as soon as they grow into the brain in early development as tight junctions are formed at this stage (Bauer et al., 1993). However, there has been some debate to the level of maturity and restrictiveness of the barriers in the developing animal. While there have been studies showing less complex tight-junctions in the embryo (Kniesel et al., 1996), others have shown that the tightjunctions are functional early in development (Ek et al., 2003, 2006; Daneman et al., 2010). However, it may be more helpful to view the $\mathrm{BBB}$ in relation to the different needs for a developing brain than a simple issue of being less or more restrictive. The developing brain barriers have been shown to be different in many aspects to the adult barriers and include a fetal specific ependymal barrier (Fossan et al., 1985), higher inward transport of both glucose (Cornford and Cornford, 1986) and amino acids (Braun et al., 1980; Tuor et al., 1992) into the developing brain as well as developmental changes in the complement and expression of drug efflux transporters (Ek et al., 2010). However, there are still many undetermined functional aspects of the developing 
blood-CSF/brain barriers. Some of these differences may very well make the developing brain more vulnerable to various insults, in fact, sheep studies have shown that the BBB becomes less susceptible to hyperosmolaric stress with development (Stonestreet et al., 2006). In rodents the BBB also appears more vulnerable to hypoxia-ischemia at early stages of development (Muramatsu et al., 1997).

\section{Tight junctions and adherence junctions}

A tight junctional complex exists between the cerebral endothelial cells. They provide a critical structural component that impedes the diffusion of molecules from the blood vessel lumen into the brain parenchyma and are composed of both cytoplasmic proteins (e.g., ZO-1 and 2) and transmembrane proteins such as claudins and occludin (Ballabh et al., 2004b, 2005; Kaur and Ling, 2008). There are also adherence junctions located near endothelial cells holding neighboring cells together. They are composed with cadherin-catenins complex and their associated proteins (Schulze and Firth, 1993).

The claudin family consists of 24 members that bind to each other on adjacent endothelial cells to form a primary seal of tight junctions (Furuse et al., 1999), with claudin-1 and claudin-5 being highly expressed in cerebral capillaries (Furuse et al., 1999). Claudin-5 is expressed as early at 12 weeks gestation in the telencephalon of the human fetus (Virgintino et al., 2004), and only claudin-5 (not claudin-1) is consistently expressed from 16 to 40 weeks gestation in the developing human brain (Ballabh et al., 2005).

Occludin is highly expressed by brain capillary endothelial cells, and their presence is related to increased electrical resistance across the barrier. Occludins appear to be able to alter paracellular permeability with increased expression being indicative of greater barrier properties (Furuse et al., 1993; Hirase et al., 1997). Occludin is expressed as early as 12 weeks gestation in the developing human brain with no change in expression for the duration of pregnancy (Virgintino et al., 2004; Ballabh et al., 2005). These findings show that key tight junctional proteins are present early in human development and imply that functional tight junctions are in place.

There are also a number of other junctional adhesion molecules (JAMs) that are important for tight junction assembly and integrity (Martin-Padura et al., 1998; Bazzoni, 2003). Three JAM proteins exist: JAM-1, JAM-2, and JAM-3, although JAM-2 has not been seen to be expressed in cerebral blood vessels to date (Aurrand-Lions et al., 2001). Ballabh et al. (2005) found JAM-1, but not JAM-2 or JAM-3, was expressed from 16 weeks, with no change of expression across gestation. The most abundant cytoplasmic accessory group of proteins are ZO, important for the structural support of tight junctions (Stevenson et al., 1986).

\section{Astrocytes and pericytes}

Astrocyte end-feet ensheath blood vessels in the brain, separated from the endothelial cell plasma membrane only by the basement membrane (Risau and Wolburg, 1990; Risau, 1991; Bernstein and Karp, 1995; El-Khoury et al., 2006). This "glial sheath" is important for cerebral vascular structure and function (Bradbury, 1984; Willis et al., 2004). Regions with a discontinuous ensheathment of astrocytes show incomplete or disintegrated basement membrane in vitro (Wolff et al., 1974). Absence of the endothelial cell-astrocyte interaction produces areas that are more permeable, such as the circumventricular regions in the hypothalamus and brainstem (Coomber and Stewart, 1984; Goldstein, 1988; Hamm et al., 2004). El-Khoury et al. (2006) investigated astrocyte end-feet coverage in the germinal matrix, white matter and cortex of human fetuses from 16 to 40 weeks gestation using GFAP (a cytoskeleton protein forming the intermediate filament), S-100 $\beta$ (cytosolic calcium binding protein), and aquaporin-4 (AQP4; water channel protein). Remarkably, they found that in the germinal matrix, a region vulnerable to hemorrhage in preterm infants, relatively fewer end-feet and astrocyte processes were labeled with GFAP or S-100 $\beta$, although this did increase across gestation. The cortex and white matter showed strong perivascular coverage from 16 weeks gestation. However, it should be noted that although astrocyte-endothelial cell contacts are present from very early in brain development, the presence of barrier properties including tight junctional proteins appear to precede these contacts (Daneman et al., 2010), making it more likely that these contacts have regulatory roles at the BBB.

Pericytes are cells that wrap around endothelial cells and provide structural support, stability, and integrity to the vessel wall (Ballabh et al., 2004b; Nakagawa et al., 2007; Kaur and Ling, 2008). Important in vasculogenesis, pericytes are recruited to endothelial cells and are important for both blood vessel and BBB development (Balabanov and Dore-Duffy, 1998). Pericytes are present in the cerebrovasculature from as early at 10 weeks gestation. In comparison to the cortex and white matter, the germinal matrix has fewer pericytes present throughout gestation (Povlishock et al., 1977; Braun et al., 2007), a feature that may be related to the vulnerability of the germinal matrix to hemorrhage in preterm neonates. A distinctive feature of pericytes is their pluripotency, as they exhibit multipotential stem cell activity, phagocytic activity and even express macrophage markers (Balabanov et al., 1996; Dore-Duffy et al., 2006; Bautch, 2011). Findings by Daneman et al. (2010) have clarified the role of the pericytes at the BBB in the developing animal. PDGFR-B null mice have reduced pericyte coverage of cerebral vessels, and this is associated with higher BBB permeability due to increased endothelial vesicular trafficking.

Functionally, pericytes may also be involved in cerebral autoregulation (Hamilton et al., 2010) as they express receptors for, and are modulated by catecholamines, endothelin-1, and vasopressin (van Zwieten et al., 1988; Elfont et al., 1989; Dehouck et al., 1997; Balabanov and Dore-Duffy, 1998; Ballabh et al., 2004b). Pericytes and endothelial cells communicate via gap junctions and their interaction is important for induction of the contractile function that ultimately modulates cerebral blood flow; for detailed reviews see (Hirschi and D'Amore, 1996; Balabanov and Dore-Duffy, 1998; Bergers and Song, 2005; DoreDuffy, 2008).

\section{CONSEQUENCE OF HYPOXIA ON CEREBRAL BLOOD VESSELS}

During development any perturbations, such as hypoxia, can significantly alter the expression of key angiogenic genes (Ment et al., 
1997; Mu et al., 2003; Kaur et al., 2006a; Keogh et al., 2007) and could thereby result in a dysfunctional vascular system. In the adult brain, severe hypoxia-ischemia such as that seen in stroke may result in breakdown of the endothelial-dependent BBB and physical destruction of the capillary bed, resulting in tissue reactions that include angiogenesis, neovascularization and vascular remodeling (del Zoppo and Mabuchi, 2003), responses that could be seen to be reparative and even neuroprotective. However, the effects of hypoxia on cerebral blood vessels in fetal life has not been widely investigated. Much of what we know is from adult rodent studies and is detailed below.

\section{ENDOTHELIAL PROGENITOR CELLS}

In response to hypoxia-sensitive molecular cues, new blood vessel formation, in the adult brain at least, is thought to occur exclusively from angiogenesis. In many adult tissues, hypoxia also induces an inflammatory response within the vessel wall, with subsequent recruitment of circulating EPCs contributing significantly to structural remodeling of the vascular bed. With the discovery of EPCs, it has now been shown that neovascularization after focal cerebral ischemia can also occur via vasculogenesis-the de novo process of blood vessel formation by differentiation and migration of EPCs in response to local cues. EPCs can home to local tissue injury and participate in damage repair or wound healing by secreting a number of growth factors that result in neovascularization.

Moreover, systemic administration of cord blood-derived EPCs in adult mice results in significant reduction of infarct volume, decreased neutrophil infiltration, and increased focal blood flow at $48 \mathrm{~h}$ after the ischemic insult (Ohta et al., 2006). EPCs have been shown to home to the ischemic core and promote both cerebral neovascularization and neuronal progenitor cell migration and survival (Zhang et al., 2002a), thereby improving cortical expansion after cell transplantation (Taguchi et al., 2004). Furthermore, the pre-existing level of circulating EPCs correlate inversely with cerebral infarction, and positively correlate with regional cerebral blood flow in patients with cerebral ischemia (Ohta et al., 2006), suggesting that EPCs have a functional predictor value for how the cerebral vasculature will be affected by hypoxia-ischemia. Indeed, the level of circulating EPCs and their migratory activity can serve as a marker for the risk of a number of cardiovascular diseases, and as a predictor of vascular function in many diseases (Sen et al., 2011).

Recently, bone marrow-derived EPCs have been shown to be mobilized, recruited and incorporated into ischemic tissue, resulting in neovascularization of ischemic foci in the brain. Furthermore, low circulating EPC level have been found to be predictive of severe neurological impairment by $48 \mathrm{~h}$ post-insult, and of the major adverse clinical outcomes on day 90 after acute ischemic stroke, consistent with the finding that increased levels of circulating EPCs after acute ischemic stroke are associated with good functional outcome and reduced infarct growth (Sobrino et al., 2007). Furthermore, hyperoxia impairs EPC signaling and decreases in vitro proliferation of EPCs from preterm infants (Fujinaga et al., 2009), decreases vessel density and reduces of circulating EPCs levels in neonatal mice (Balasubramaniam and
Del Bigio, 2006), suggesting that oxygen therapy in the newborn period could impair the physiological actions of EPCs.

\section{HYPOXIA-INDUCED ANGIOGENESIS AND VASCULAR REMODELING}

In the adult, chronic hypoxia induces angiogenesis, presumably a response aimed at increasing vascularization and oxygen delivery to oxygen-deprived tissue (Shweiki et al., 1993). This process occurs in tumor growth (Kim et al., 1993; Breier and Risau, 1996; Banerjee et al., 1997; Breier, 2000), wound healing (Bates and Jones, 2003; Otrock et al., 2007), diabetic retinopathy (Boulton et al., 1998; Aiello, 2005), and following stroke (Krupinski et al., 1994; Zhang et al., 2000; del Zoppo and Mabuchi, 2003). Neovascularization and vascular remodeling are tightly regulated processes, and in the brain there is a complex interplay of multiple genes; e.g., hypoxia inducible factor-1 (HIF$1 \alpha$ ), VEGF and erythropoietin (Epo) expressed by different cell types (Marti et al., 2000). Following stroke, regions of high angiogenesis have also been correlated with increased neuronal survival (Krupinski et al., 1994). Although hypoxia-induced angiogenesis is thought to be a protective in the sense that more oxygen is delivered to hypoxic-ischemic tissue, there are associated effects such as alterations in BBB permeability that are not necessarily beneficial (see below). Several key molecules for regression and re-growth of capillary blood vessels have been identified including VEGF, Placental Growth factor, acidic-FGF, TNF- $\alpha$, IL-8, and angpts. The consequence of hypoxia-induced angiogenesis in the fetal and neonatal brain is yet to be fully determined.

Angiogenic remodeling refers to the process by which this initial network is modified, through both pruning and vessel enlargement in order to form the interconnecting branching patterns characteristic of the mature (stable) vasculature. During this time, vessel walls also "mature" in the sense that endothelial cells become tightly integrated with supporting cells such as smooth muscle cells and pericytes, and with the surrounding matrix. A different process, referred to as angiogenic sprouting, involves the formation of new vascular tubes from existing vessels and their penetration into new vascular territory, and this involves degradation of the existing vessel, and the formation of new structures which, being initially incomplete, can be said to be "immature." The degradation and destabilization of blood vessels, which includes degradation of the basal membrane and extracellular matrix, and also pericyte detachment, can lead to $\mathrm{BBB}$ disruption, edema formation, and mechanical rupture, and thus bleeding. The cellular and molecular processes involved vary and depend on the cellular composition of vessels as well as on local environmental factors. Each of the resident vascular cell types (i.e., pericytes, endothelial, smooth muscle) undergo siteand time-dependent changes in proliferation, matrix protein production, expression of growth factors, cytokines, and receptors, and each resident cell type plays a specific role in the overall remodeling response. However, effects of hypoxia on, and vascular responses to fetal hypoxia that cause brain damage are poorly understood.

\section{HYPOXIA INDUCIBLE FACTORS}

In response to hypoxia, HIF-1, a key regulator of oxygen homeostasis is transcriptionally activated to improve oxygen 
availability (Semenza, 2009b). Increased HIF-1 $\alpha$ also contributes to increased expression of angiogenic genes, including VEGF, angpt-2, PDGF-B, and PIGF (Fan et al., 2009; Semenza, 2009b). The robust up-regulation of these genes may act as possible biomarkers in the neonate of a previously undetected hypoxicischemic event in the fetus prior to delivery.

Composed of $\alpha$ and $\beta$ subunits, once in the nucleus, HIF$1 \alpha$ dimerises with HIF- $1 \beta$ and binds to target genes (including Epo and VEGF) at their hypoxia response element (Semenza, 2009b). Three alpha isoforms exist; HIF-1 $\alpha$, HIF-2 $\alpha$, and HIF$3 \alpha$, although less is known about the actions of the $2 \alpha$ and $3 \alpha$ isoforms compared to HIF- $1 \alpha$. HIF- $1 \alpha$ is expressed in many cell types throughout the body whereas, and perhaps importantly for the current discussion, expression of HIF- $2 \alpha$ is restricted to vascular endothelial cells (Wiener et al., 1996; Semenza, 2009b; Skuli et al., 2009).

During embryonic and fetal brain development physiological hypoxia stimulates vasculogenesis and angiogenesis, mediated by HIF (Trollmann and Gassmann, 2009). HIF-1 $\alpha$ knockout mice show impaired erythropoiesus (among other impairments) and die by embryonic day 8.5 (Iyer et al., 1998; Semenza, 2009a). HIF$2 \alpha$ endothelial deletion shows normal development, but increased vascular permeability, and decreased angpt-2 expression and angiogenesis (SkuLi et al., 2009). It is therefore, suggested that in endothelial cells, HIF- $1 \alpha$ may be important for proliferation, metabolism, and survival, whereas HIF- $2 \alpha$ could trigger cell migration, adhesion and vascular integrity (Skuli and Simon, 2009).

Following hypoxia in the neonatal brain, HIF-1 $\alpha$ predominantly accumulates first in neurons, perhaps because they are most sensitive to fluctuations in oxygen, but sustained high expression of HIF-1 $\alpha$ in neurons has been shown to be protective and anti-apoptotic (Fan et al., 2009; Trollmann and Gassmann, 2009). Following neonatal hypoxia-ischemia, mice who had a genetic neuronal knockdown of HIF-1 $\alpha$ had worse injury compared to wild type controls (Sheldon et al., 2009). However, inhibition of HIF-1 $\alpha$ soon after hypoxia-ischemia has been shown to decrease infarct size, attenuate $\mathrm{BBB}$ permeability changes and neuronal death in neonatal rats (Chen et al., 2008), indicating that the actions of HIF-1 $\alpha$ are time-dependent.

\section{IMPLICATIONS OF VEGF}

The response of VEGF following hypoxia and/or hypoxia-ischemia has been widely studied in the adult (Cobbs et al., 1998; Lennmyr et al., 1998; Plate et al., 1999; Marti et al., 2000; Zhang et al., 2000, 2002b; Sun et al., 2003) and to a lesser extent in the developing brain (Ment et al., 1997; Arai et al., 1998; Mu et al., 2003; Kaur et al., 2006a; Alyetal., 2009). As previously described, a potent stimulator and key transcriptional regulator of VEGF expression is HIF- $1 \alpha$ (Forsythe etal., 1996; MartiandRisau, 1998). However,itwasrecentlyobserved that the up-regulation of VEGF in astrocytes following hypoxia is not entirely HIF-1 $\alpha$-dependent (Schmid-Brunclik et al., 2008), and others have shown that peroxisome-proliferator-activated receptor-gamma coactivator-1alpha (PGC-1 $\alpha$ ) induces VEGF expression-independently of HIF-1 $\alpha$ (Arany et al., 2008). Hypoxiainduced VEGF expression in the brain can have both neuroprotective and neurotoxic actions (Figure 2). This has been recently reviewed by several authors (Carmeliet and Storkebaum, 2002; Skold and Kanje, 2008; Hermann and Zechariah, 2009) and is briefly summarized below.

\section{Neurotoxic actions of VEGF}

Increased circulating serum VEGF from umbilical cord blood of infants who had experienced birth asphyxia was strongly correlated with hypoxic-ischemic encephalopathy (HIE) and lower Apgar scores (Aly et al., 2009). Elevated circulating VEGF from CSF and placenta samples was also shown to have a strong positive correlation with severity of HIE (Trollmann et al., 2003; Vasiljevic et al., 2011). Arai et al. (1998) also found increased astrocytic and endothelial expression of VEGF in the foci of necrosis in infants who suffered PVL. From postnatal rat studies of either hypobaric (chronic or acute) hypoxia or middle cerebral artery occlusion (MCAO), increased VEGF expression was seen as quickly at $3 \mathrm{~h}$ following the insult to being sustained for up to 7 days (Ment et al., 1997; Ogunshola et al., 2000; Mu et al., 2003; Kaur et al., 2006a). Following hypobaric hypoxia in neonatal mice, high VEGF expression is seen together with increased eNOS, iNOS, and nNOS expressions, suggesting a contribution of nitrogen free radicals to both cerebral vasodilation and excitotoxicity (Kaur and Ling, 2009). Astrocytic and neuronal expression of VEGF is high following hypoxia when compared to normoxic controls, high neuronal VEGF expression following hypoxia is also seen in the adult (Marti and Risau, 1998; Ogunshola et al., 2000).

The most profound consequence of increased VEGF expression is the increased vascular permeability, leading to vasogenic edema and the leakage of blood-borne substances into the brain parenchyma (Schoch et al., 2002; Kaur et al., 2006b). In adult models of global hypoxia, focal cerebral ischemia and brain trauma, increased BBB leakage was associated with acute upregulation of VEGF (Nag et al., 1997; Zhang et al., 2000, 2002b; Schoch et al., 2002; Kaur et al., 2006b), and the increased expression of VEGF in astrocytes is suggested to contribute to this BBB leakage (Schmid-Brunclik et al., 2008). Intravenous administration of VEGF in the newborn mouse has also shown to open the BBB within $2 \mathrm{~h}$ (Young et al., 2004). VEGF has a direct action on endothelial cells and pericytes, and pericytes have been implicated in exacerbating disruption of the BBB (Hippenstiel et al., 1998; Yamagishi et al., 1999; Al Ahmad et al., 2009; Thanabalasundaram et al., 2010), possibly because they are amongst the first cells to respond by moving away from the blood vessel wall, and by producing factors such as VEGF which are thought to contribute to vascular instability (Gonul et al., 2002; Al Ahmad et al., 2009; Thanabalasundaram et al., 2010). In brain microvascular endothelial cells, the disruption and disassembly of tight junction proteins occludin and ZO-1 is VEGF mediated (Wang et al., 2001). Fischer et al. (2002) also found that VEGF mediates changes in ZO-1 expression following hypoxia.

\section{Neuroprotective actions of VEGF}

Hypoxia-induced angiogenesis occurs in an attempt to increase vascularization, to increase cerebral blood flow, and oxygenation in ischemic tissue. VEGF can increase the survival of endothelial cells as well as stimulate and sustain neurogenesis and inhibit 


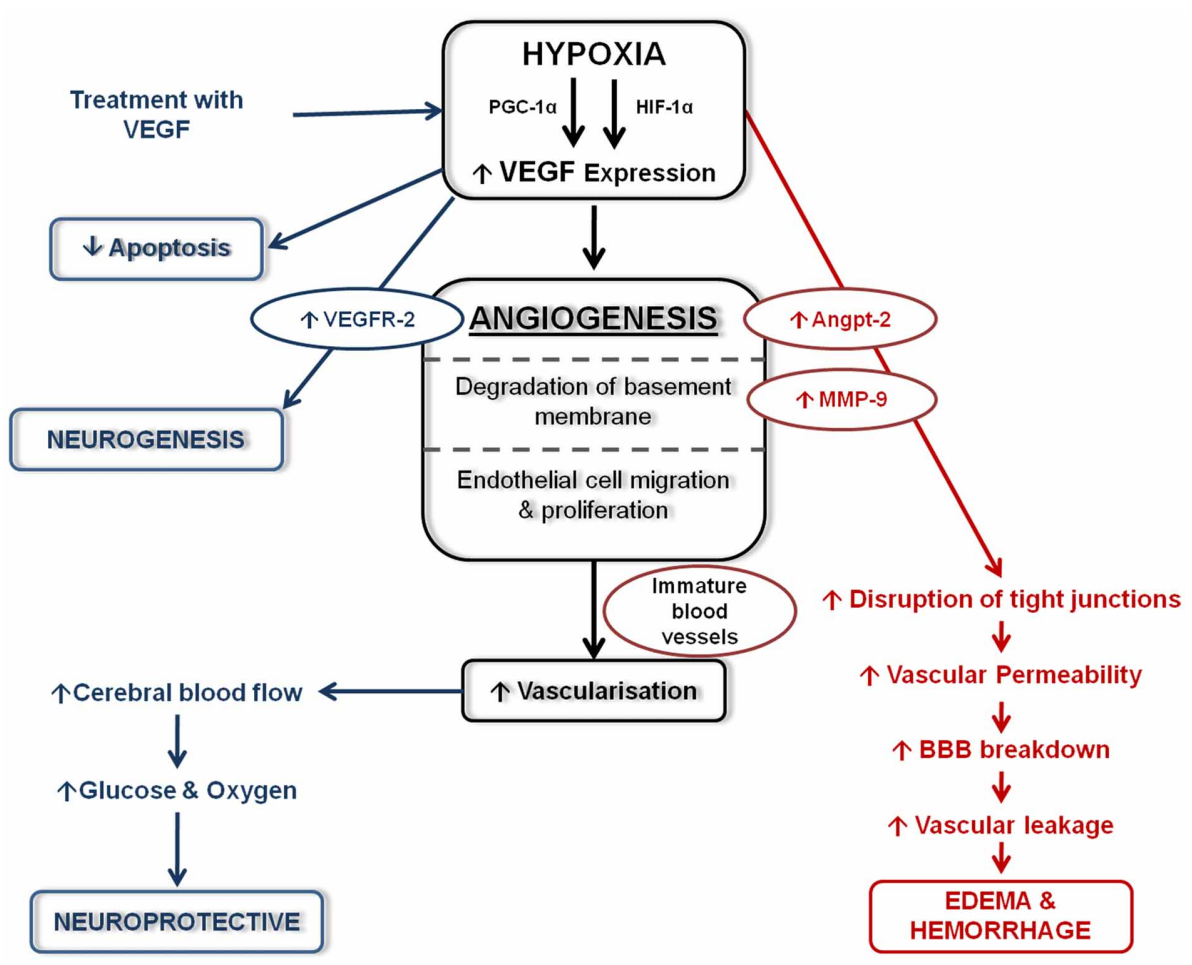

FIGURE 2 | Schematic diagram of the effects of VEGF following hypoxia. Following hypoxia, increased VEGF expression stimulated angiogenesis leading to increase vascularization. Increased VEGF expression can have detrimental effects (shown in red) which can lead to edema and haemorrhage formation. Beneficial effects of increased VEGF (shown in blue) help stimulate neurogenesis, decrease apoptosis and are neuroprotective. apoptosis (Gora-Kupilas and Josko, 2005). Schmid-Brunclik et al. (2008) also found that following hypoxia VEGF contributes to astrocyte proliferation and survival.

Experimental studies from the adult brain suggest that the "early" up-regulation (between $1 \mathrm{~h}$ and $3 \mathrm{~h}$ post-MCAO) of VEGF could be associated with alterations in BBB permeability and contribute to exacerbating injury. The neuroprotective actions of VEGF including neovascularization and neuronal protection are more likely to occur in the days (after $48 \mathrm{~h}$ ) following hypoxia (MCAO), when both VEGF and VEGFR-2 have been shown to be up-regulated (Marti et al., 2000). Most interestingly, it is studies that use VEGF treatment that show the best neuroprotective outcome. In both neonatal and adult models following hypoxia, intra-cerebroventricularly injection of VEGF resulted in reduced gross brain injury, subsequently alleviating the decrease in brain weight (i.e., decreased infarct volume), decreased apoptotic cells without increasing BBB permeability. Both studies suggest this is related to the activation of the Akt/ERK pathway (Kaya et al., 2005; Feng et al., 2008). Inhibition of VEGFR-2 has also been shown to decrease endothelial cell proliferation, increase cell death and worsen injury following neonatal stroke in rodents (Shimotake et al., 2010).

Studies from the neonatal rat following hypobaric hypoxia (Kaur et al., 2006a) and MCAO (Mu et al., 2003) have found that VEGF is up-regulated leading to increased vascular permeability as well as possibly being neuroprotective.

\section{ERYTHROPOIETIN}

Another key hypoxia inducible gene is Epo which, following hypoxia is increasingly important for regulating red blood cell production to increase the capacity of red blood cells to transport and ultimately increase oxygen supply (Marti, 2004; Fan et al., 2009). Hypoxic up-regulation of Epo is regulated by HIF$1 \alpha$, however, growing evidence suggests HIF- $2 \alpha$ may also play a significant role is transcriptionally regulating Epo expression in the brain in vivo and in cultured astrocytes in vitro (Chavez et al., 2006; Yeo et al., 2008; Fan et al., 2009). Epo is widely expressed in the brain by astrocytes, neurons, microglia, and endothelial cells (Bernaudin et al., 1999; Marti, 2004; Castillo-Melendez et al., 2005). Following cerebral ischemia, endothelial cells are the first to increase Epo expression (Bernaudin et al., 1999), which could implicate Epo as being important for the vasculature following hypoxia. More recently, it has been reported that Epo mediated angiogenesis can occur by stimulating the expression of VEGF and its' receptor on endothelial cells (Iwai et al., 2007; Hermann and Zechariah, 2009). In vitro, Epo can modulate angiogenesis by stimulating endothelial cell migration and proliferation (Anagnostou et al., 1990; Yamaji et al., 1996).

Suggested to be neuroprotective following hypoxia, increased Epo expression has also been shown to increase anti-apoptotic gene expression and promote survival in oligodendrocytes, neurons, astrocytes, and microglia (Marti, 2004; Fan et al., 2009). Treatment with recombinant human Epo following focal 
hypoxia-ischemia in neonatal rats results in enhanced revascularization, neurogenesis, endothelial cell and neuronal survival and increased Glut-1, Tie-1, and angpt-2 expression which resulted in enhanced neurovascular unit repair (Iwai et al., 2007; Keogh et al., 2007). Epo treatment following neonatal stroke in rats has also shown significant neuroprotection (Chang et al., 2005; Gonzalez et al., 2007).

\section{ANGIOPOIETINS}

There is a close interaction between VEGF and angpt ( -1 and -2$)$ expression following hypoxia. Down-regulation of angpt-1, important for blood vessel stabilization, occurs in response to hypoxia, and this correlates with increased BBB permeability and vascular leakage (Zhang et al., 2002b; Valable et al., 2005). Whether vascular remodeling or regression occurs following cerebral ischemia in the adult (rat) is dependent upon the presence of VEGF. Increased angpt-2 and VEGF expression by blood vessels promotes vascular growth; however, vascular regression occurs in the absence of VEGF (Beck et al., 2000). Up-regulation of Tie-1 and Tie-2, the angpt receptors, persists for up to 2 weeks following MCAO and this correlates closely with increased angpt-1 and angpt-2 expression resulting in neovascularization (Lin et al., 2000, 2001). However, increased angpt-2 expression can also persist with no change in angpt-1 or Tie-2 expression following $\mathrm{MCAO}$, or during chronic hypobaric hypoxia in the adult rat (Beck et al., 2000; Pichiule and LaManna, 2002).

\section{DEGRADATION OF BASAL LAMINA}

Degradation of laminin is consistent with disruptions of the BBB (Figure 3) and can contribute to edema formation and hemorrhage (del Zoppo and Mabuchi, 2003; Veltkamp et al., 2006). Degradation of the basal lamina following hypoxia is due to plaminogen-plasmin system and the MMP-2 and 9. MMPs belong to a family of proteins that control tissue degradation (Hamann et al., 1995; Burk et al., 2008). Following hypoxiaischemia, MMP-9 is up-regulated, and laminin being a substrate, is thought to result in the laminin degradation that may then follow (Zalewska et al., 2002). Following ischemia, decreased collagen IV is associated with increased infarct volume and changes in BBB permeability (Hamann et al., 1995, 2002; Scholler et al., 2007). However, another basement membrane constituent fibronectin, and its' $\alpha 5 \beta 1$ integrand receptor, are also up-regulated in endothelial cells following hypobaric hypoxia in the adult, possibly highlighting an angiogenic role for this glycoprotein (Milner et al., 2008).

\section{COMPROMISE OF THE BLOOD BRAIN BARRIER}

Studies in rodent models of neonatal hypoxia-ischemia have indicated that the BBB is compromised as a result of such insults (Muramatsu et al., 1997; Svedin et al., 2007; Ferrari et al., 2010b; Tu et al., 2011; Yang et al., 2012). In addition, CSF samples from HIE infants have been shown to have albumin CSF/plasma concentration ratios that are $\sim 5$ times higher than normal (Kumar et al., 2008), suggesting a dysfunctional BBB in the HIE infants. The animal studies have mostly relied on the extravasation of plasma proteins into brain parenchyma to examine BBB breakdown making the exact timing and magnitude of breakdown after the insult difficult to ascertain. Ferrari et al. (2010b) who used sodium fluorescein uptake into the brain to assess barrier permeability, reported that after hypoxic-ischemic insult in P7 rats there was an increase in BBB permeability at 1 and 7 days after the insult, but it was restored to normal at 21 days. All these studies do suggest that hypoxia-ischemia related injury to the developing brain is associated with compromise to the barrier, however, what role this has in determining the pathological outcomes is still unclear.

Modification of tight junction proteins may be a cause of changes to BBB permeability following hypoxia-ischemia (Figure 3). Malaeb et al. (2007) determined the level of tight junctional proteins after cerebral ischemia in late gestational sheep. Cortical samples showed that these proteins were differentially regulated after the insult with higher claudin-5 levels, but lower ZO-1/2 levels. Adult studies of cerebral ischemiareperfusion have also shown that this is associated with changes to the levels of tight junction proteins in cerebral vessels (Witt et al., 2003). Studies in rats by Muramatsu et al. (1997) showed that the BBB was more vulnerable to a hypoxic-ischemic insult in younger (P7 day) compared to older (P21 day) rat pups, and as mentioned above, this susceptibility may be related to several developmental aspects of the formation of the neurovascular unit. The severity of oxygen deprivation contributes to the rate of loss of $\mathrm{BBB}$ function during acute hypoxic exposure (Al Ahmad et al., 2009). However, in a model of hypoxia in the newborn piglet $\mathrm{BBB}$ integrity, measured as permeability to small ions, was maintained (Stonestreet et al., 1992).

Figure 3 summarizes the consequence of hypoxia on the components of the neurovascular unit. As mentioned previously, increased VEGF expression following hypoxia-ischemia results in compromise of BBB permeability. Synthesis and release of soluble guanylate cyclase, NO, tissue type plasminogen activator, prostaglandins (PG) and increased calcium influx all contribute to changes in vascular permeability (Bates and Curry, 1997; Murohara et al., 1998; Mayhan, 1999; Yang et al., 2009).

Pericytes are some of the first cells to respond to hypoxia, within the hours following hypoxia in the adult, some pericytes also migrate away from vessels (Gonul et al., 2002) resulting in decreased vascular support. In vitro and in vivo studies have shown that pericytes can express VEGF and exacerbate BBB disruption following acute hypoxia (Yamagishi et al., 1999; Al Ahmad et al., 2009, 2011). Pericytes can also express angpt-1, but whether pericyte migration occurs in the fetal brain following hypoxia, in regions of $\mathrm{BBB}$ compromise could reveal the basis of vascular fragility (leading to an increased propensity to rupture).

\section{Edema formation}

Following hypoxia, BBB leakage triggers the activation of astrocytes, corresponding with an increase in AQP4, an astroglial water channel which facilitates water movement in and out of the brain, a response that is likely to be involved in the formation of edema (Kaur et al., 2006b; Ferrari et al., 2010a,b). Two forms of edema exist; cytotoxic and vasogenic edema. Cytotoxic edema is swelling of cellular elements and is suggested to occur in severe cardiovascular and hypoxic collapse seen following pneumothorax (Temesvari et al., 1984; Klatzo, 1987). Vasogenic edema 


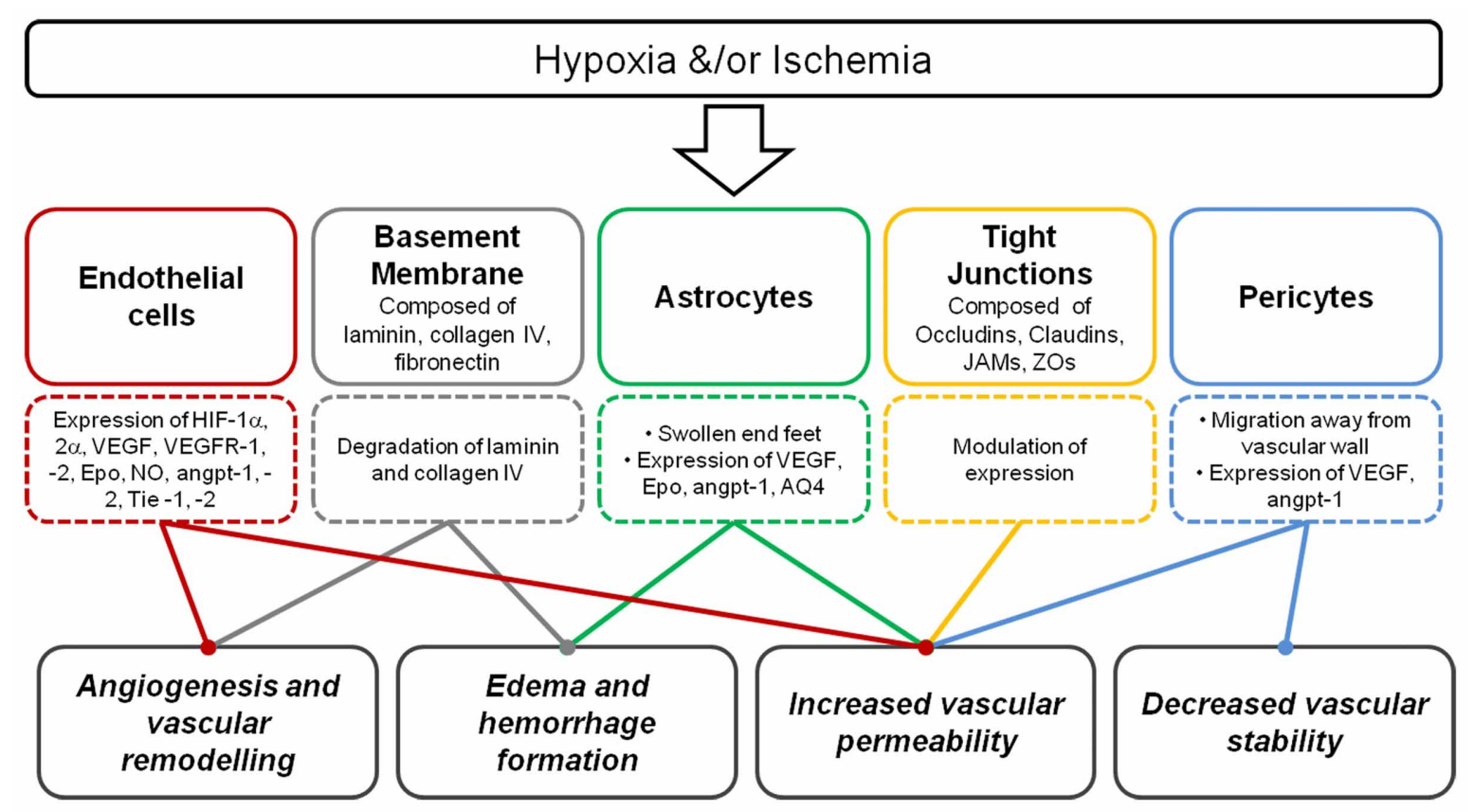

FIGURE 3 | Summary of the consequence of hypoxia and/or ischemia on the neurovascular unit. Following hypoxia, endothelial cells express a range of key hypoxic and angiogenic factors, basement membrane degradation occurs, astrocyte end-feet become swollen, modulation of tight junction expression occur and pericytes may migrate away. These responses contribute to angiogenesis, vascular remodeling, edema, and hemorrhage formation, increased vascular permeability, and decreased vascular stability. is associated with increased vascular permeability, retention of water and entry of serum proteins into the brain parenchyma (Klatzo, 1987). Disruptions in BBB permeability, elevation in mean arterial blood pressure and subsequent accumulation of water content into the brain parenchyma all contribute to the formation of vasogenic edema (Kuroiwa et al., 1985; Klatzo, 1987).

Utilizing MRI, clinical studies have found that following severe perinatal asphyxia more than $80 \%$ of term neonates develop brain edema (Boichot et al., 2006), which has also been shown to be strongly associated with poor neurological outcome (Chang et al., 2007). From rodent studies, neonatal hypoxia-ischemia resulted in a biphasic edema formation occurring initially as early as $2 \mathrm{~h}$ and persisting after $24 \mathrm{~h}$. This was seen to correspond with an "early" neuronal injury and "late" glial damage (Nedelcu et al., 1999).

\section{CURRENT CLINICAL THERAPIES AND THE INFLUENCE ON CEREBRAL BLOOD VESSELS}

As well as understanding the response of cerebral blood vessels following hypoxia-ischemia, it is importantly to briefly detail the implications of the current clinical therapies given for preterm birth and possibly reduced injury following hypoxia-ischemia.

\section{GLUCOCORTICOIDS}

Prenatal glucocorticoids are routinely administered to women who are at risk of preterm birth, in an attempt to hasten fetal lung maturation, especially with respect to surfactant production. They have been shown to reduce respiratory distress syndrome and intraventricular hemorrhage (Liggins and Howie,
1972; Shankaran et al., 1995). The possible mechanisms that may contribute to this protection have been elegantly investigated by Vinukonda et al. (2010). They found that glucocorticoid treatment resulted in decreased endothelial proliferation and vascular density but increased pericyte coverage in the germinal matrix of human preterm infants. In vivo studies in neonatal rats have shown that dexamethasone treatment prior to hypoxia-ischemia increased VEGF protein, reducing brain injury, decreased caspase- 3 activity and DNA fragments (Feng et al., 2011). Interestingly, maternal treatment with glucocorticoids such as dexamethasone has shown to also up-regulate key tight junctional proteins and decrease BBB permeability in the ovine fetus (Stonestreet et al., 1999; Sadowska et al., 2010), consistent with in vitro studies that also show up-regulation of angpt-1 and down-regulation of VEGF in astrocytes and pericytes following dexamethasone treatment (Kim et al., 2008). However, dexamethasone treatment had no effect on expression of angpt-1, -2 or VEGF expression by endothelial cells (Kim et al., 2008). The implications of these studies are that glucocorticoids, routinely used to mature the preterm lung, could have direct beneficial effects on the preterm cerebral circulation. However, it must be considered also that the greater ease with which preterm neonates are resuscitated and ventilated may mean that the mechanical and cardiorespiratory disturbances are lessened, so that wide fluctuations of cerebrovascular perfusion are somewhat avoided.

\section{HYPOTHERMIA}

Brain and/or body cooling is becoming a routine practice for infants that have suffered birth asphyxia. Hypothermia decreases 
cerebral metabolism, and thereby delays cell death. One study has shown that following permanent MCAO in the adult rodent, mild hypothermia resulted in decreased infarct size and enhanced angiogenesis (Xie et al., 2007). It has been suggested that hypothermia may therefore, play a beneficial role with regards to angiogenesis in the sub-acute (hours to days) and chronic (weeks to months) stages following hypoxia-ischemia (Yenari and Han, 2012). There are also studies indicating that hypothermia restores BBB function after hypoxia-ischemia, but this seems only to have been studied after ischemia in the adult. Hypothermia can reduce the activation of MMPs (Truettner et al., 2005) which can degrade tight junctional proteins and it can also delay pericyte migration away from the endothelial cell (Duz et al., 2007).

\section{SUMMARY}

This review summarizes current knowledge regarding the response of the vasculature and the $\mathrm{BBB}$ in the fetal and newborn brain to hypoxia and/or ischemia. Although the studies of the developing brain are limited in comparison to the adult brain, the findings indicate that hypoxia-ischemia has significant effects on the immature cerebral vasculature, perhaps explaining some of the regional vulnerability of the perinatal brain to injury. The key mediators of injury mentioned in this review also reveal great therapeutic potential, not only for early biomarkers of brain injury, but also for designing clinical treatments that might be used both prior to or following hypoxia to protect the immature brain from permanent damage.

\section{ACKNOWLEDGMENTS}

The authors wish to acknowledge funding support from NHMRC Australia, Cerebral Palsy Alliance Australia, the Victorian Government's Operational Infrastructure Support Program to Monash Institute of Medical Research, Australia, and European Union grant FP7 (Neurobid, HEALTH-F2-2009-241778).

\section{REFERENCES}

Abbott, N. J., Patabendige, A. A., Dolman, D. E., Yusof, S. R., and Begley, D. J. (2010). Structure and function of the blood-brain barrier. Neurobiol. Dis. 37, 13-25.

Aiello, L. P. (2005). Angiogenic pathways in diabetic retinopathy. $N$. Engl. J. Med. 353, 839-841.

Al Ahmad, A., Gassmann, M., and Ogunshola, O. O. (2009). Maintaining blood-brain barrier integrity: pericytes perform better than astrocytes during prolonged oxygen deprivation. J. Cell. Physiol. $218,612-622$.

Al Ahmad, A., Taboada, C. B., Gassmann, M., and Ogunshola, O. O. (2011). Astrocytes and pericytes differentially modulate blood-brain barrier characteristics during development and hypoxic insult. J. Cereb. Blood Flow Metab. 31, 693-705.

Alonso, A., Reinz, E., Fatar, M., Hennerici, M. G., and Meairs, S. (2011). Clearance of albumin following ultrasound-induced blood-brain barrier opening is mediated by glial but not neuronal cells. Brain Res. 1411, 9-16.

Alvarez-Diaz, A., Hilario, E., De Cerio, F. G., Valls-I-Soler, A., and AlvarezDiaz, F. J. (2007). Hypoxic-ischemic injury in the immature brainkey vascular and cellular players. Neonatology 92, 227-235.

Aly, H., Hassanein, S., Nada, A., Mohamed, M. H., Atef, S. H., and Atiea, W. (2009). Vascular endothelial growth factor in neonates with perinatal asphyxia. Brain Dev. 31, 600-604.

Anagnostou, A., Lee, E. S., Kessimian, N., Levinson, R., and Steiner, M. (1990). Erythropoietin has a mitogenic and positive chemotactic effect on endothelial cells. Proc. Natl. Acad. Sci. U.S.A. 87, 5978-5982.

Arai, Y., Deguchi, K., and Takashima, S. (1998). Vascular endothelial growth factor in brains with periventricular leukomalacia. Pediatr. Neurol. 19, 45-49.

Arany, Z., Foo, S. Y., Ma, Y., Ruas, J. L., Bommi-Reddy, A., Girnun, G., et al. (2008). HIF-independent regulation of VEGF and angiogenesis by the transcriptional coactivator PGC-1alpha. Nature 451, 1008-1012.

Asahara, T., Murohara, T., Sullivan, A., Silver, M., Van Der Zee, R., Li, T., et al. (1997). Isolation of putative progenitor endothelial cells for angiogenesis. Science 275, 964-967.

Aurrand-Lions, M., Johnson-Leger, C., Wong, C., Du Pasquier, L., and Imhof, B. A. (2001). Heterogeneity of endothelial junctions is reflected by differential expression and specific subcellular localization of the three JAM family members. Blood 98, 3699-3707.

Back, S. A., Gan, X., Li, Y., Rosenberg, P. A., and Volpe, J. J. (1998). Maturation-dependent vulnerability of oligodendrocytes to oxidative stress-induced death caused by glutathione depletion. J. Neurosci. 18, 6241-6253.

Back, S. A., Riddle, A., and McClure, M. M. (2007). Maturation-dependent vulnerability of perinatal white matter in premature birth. Stroke 38, 724-730.

Balabanov, R., and Dore-Duffy, P. (1998). Role of the CNS microvascular pericyte in the blood-brain barrier. J. Neurosci. Res. 53, 637-644.
Balabanov, R., Washington, R., Wagnerova, J., and Dore-Duffy, P. (1996). CNS microvascular pericytes express macrophage-like function, cell surface integrin alpha $\mathrm{M}$, and macrophage marker ED-2. Microvasc. Res. 52, 127-142.

Balasubramaniam, J., and Del Bigio, M. R. (2006). Animal models of germinal matrix hemorrhage. J. Child Neurol. 21, 365-371.

Ballabh, P. (2010). Intraventricular hemorrhage in premature infants: mechanism of disease. Pediatr. Res. $67,1-8$.

Ballabh, P., Braun, A., and Nedergaard, M. (2004a). Anatomic analysis of blood vessels in germinal matrix, cerebral cortex, and white matter in developing infants. Pediatr. Res. 56, 117-124.

Ballabh, P., Braun, A., and Nedergaard, M. (2004b). The blood-brain barrier: an overview: structure, regulation, and clinical implications. Neurobiol. Dis. 16, 1-13.

Ballabh, P., Hu, F., Kumarasiri, M., Braun, A., and Nedergaard, $M$ (2005). Development of tight junction molecules in blood vessels of germinal matrix, cerebral cortex, and white matter. Pediatr. Res. 58, 791-798.

Ballabh, P., Xu, H., Hu, F., Braun, A., Smith, K., Rivera, A., et al. (2007). Angiogenic inhibition reduces germinal matrix hemorrhage. Nat. Med. 13, 477-485.

Banerjee, S. K., Sarkar, D. K., Weston, A. P., De, A., and Campbell, D. R. (1997). Over expression of vascular endothelial growth factor and its receptor during the development of estrogeninduced rat pituitary tumors may mediate estrogen-initiated tumor angiogenesis. Carcinogenesis 18, 1155-1161.

Barkovich, A. J. (2005). Magnetic resonance techniques in the assessment of myelin and myelination. J. Inherit. Metab. Dis. 28, 311-343.

Bates, D. O., and Curry, F. E. (1997). Vascular endothelial growth factor increases microvascular permeability via a $\mathrm{Ca}(2+)$-dependent pathway. Am. J. Physiol. 273, H687-H694.

Bates, D. O., and Jones, R. O. (2003). The role of vascular endothelial growth factor in wound healing. Int J. Low. Extrem. Wounds 2, 107-120.

Baud, O., Daire, J. L., Dalmaz, Y., Fontaine, R. H., Krueger, R. C., Sebag, G., et al. (2004). Gestational hypoxia induces white matter damage in neonatal rats: a new model of periventricular leukomalacia. Brain Pathol. 14, 1-10.

Bauer, H. C., Bauer, H., Lametschwandtner, A., Amberger, A., Ruiz, P., and Steiner, M. (1993). Neovascularization and the appearance of morphological characteristics of the blood-brain barrier in the embryonic mouse central nervous system. Brain Res. Dev. Brain Res. 75, 269-278.

Bautch, V. L. (2011). Stem cells and the vasculature. Nat. Med. 17, 1437-1443.

Bazzoni, G. (2003). The JAM family of junctional adhesion molecules. Curr. Opin. Cell Biol. 15, 525-530.

Beal, M. F. (1992). Mechanisms of excitotoxicity in neurologic diseases. FASEB J. 6, 3338-3344.

Beck, H., Acker, T., Wiessner, C., Allegrini, P. R., and Plate, K. H. (2000). Expression of angiopoietin-1, angiopoietin-2, and tie receptors after middle cerebral 
artery occlusion in the rat. Am. J. Pathol. 157, 1473-1483.

Beltran, B., Mathur, A., Duchen, M. R., Erusalimsky, J. D., and Moncada, S. (2000). The effect of nitric oxide on cell respiration: a key to understanding its role in cell survival or death. Proc. Natl. Acad. Sci. U.S.A. 97, 14602-14607.

Bennet, L., Booth, L., and Gunn, A. J. (2010). Potential biomarkers for hypoxic-ischemic encephalopathy. Semin. Fetal Neonatal Med. 15, 253-260.

Bennet, L., Peebles, D. M., Edwards, A. D., Rios, A., and Hanson, M. A. (1998). The cerebral hemodynamic response to asphyxia and hypoxia in the near-term fetal sheep as measured by near infrared spectroscopy. Pediatr. Res. 44, 951-957.

Bennet, L., Rossenrode, S., Gunning, M. I., Gluckman, P. D., and Gunn, A. J. (1999). The cardiovascular and cerebrovascular responses of the immature fetal sheep to acute umbilical cord occlusion. J. Physiol. 517(Pt 1), 247-257.

Bergers, G., and Song, S. (2005). The role of pericytes in blood-vessel formation and maintenance. Neuro Oncol. 7, 452-464.

Bernaudin, M., Marti, H. H., Roussel, S., Divoux, D., Nouvelot, A., Mackenzie, E. T., et al. (1999). A potential role for erythropoietin in focal permanent cerebral ischemia in mice. J. Cereb. Blood Flow Metab. 19, 643-651.

Bernstein, J. J., and Karp, S. M. (1995). Migrating fetal astrocytes do not intravasate since they are excluded from blood vessels by vital basement membrane. Int. J. Dev. Neurosci. 14, 177-180.

Boichot, C., Walker, P. M., Durand, C., Grimaldi, M., Chapuis, S., Gouyon, J. B., et al. (2006). Term neonate prognoses after perinatal asphyxia: contributions of MR imaging, MR spectroscopy, relaxation times, and apparent diffusion coefficients. Radiology 239, 839-848.

Borghesi, A., Massa, M., Campanelli, R., Bollani, L., Tzialla, C., Figar, T. A., et al. (2009). Circulating endothelial progenitor cells in preterm infants with bronchopulmonary dysplasia. Am. J. Respir. Crit. Care Med. 180, 540-546.

Boulton, M., Foreman, D., Williams, G., and McLeod, D. (1998). VEGF localisation in diabetic retinopathy. Br. J. Ophthalmol. 82, 561-568.

Bradbury, M. W. (1984). The structure and function of the blood-brain barrier. Fed. Proc. 43, 186-190.

Braun, A., Xu, H., Hu, F., Kocherlakota, P., Siegel, D., Chander, P., et al.
(2007). Paucity of pericytes in germinal matrix vasculature of premature infants. J. Neurosci. 27, 12012-12024.

Braun, L. D., Cornford, E. M., and Oldendorf, W. H. (1980). Newborn rabbit blood-brain barrier is selectively permeable and differs substantially from the adult. $J$. Neurochem. 34, 147-152.

Breier, G. (2000). Functions of the VEGF/VEGF receptor system in the vascular system. Semin. Thromb. Hemost. 26, 553-559.

Breier, G., Albrecht, U., Sterrer, S., and Risau, W. (1992). Expression of vascular endothelial growth factor during embryonic angiogenesis and endothelial cell differentiation. Development 114, 521-532.

Breier, G., and Risau, W. (1996). The role of vascular endothelial growth factor in blood vessel formation. Trends Cell Biol. 6, 454-456.

Brightman, M. W., and Reese, T. S. (1969). Junctions between intimately apposed cell membranes in the vertebrate brain. J. Cell Biol. 40, 648-677.

Burk, J., Burggraf, D., Vosko, M., Dichgans, M., and Hamann, G. F. (2008). Protection of cerebral microvasculature after moderate hypothermia following experimental focal cerebral ischemia in mice. Brain Res. 1226, 248-255.

Carmeliet, P. (2003). Angiogenesis in health and disease. Nat. Med. 9, 653-660.

Carmeliet, P., and Storkebaum, E. (2002). Vascular and neuronal effects of VEGF in the nervous system: implications for neurological disorders. Semin. Cell Dev. Biol. 13, 39-53.

Castillo-Melendez, M., Chow, J. A., and Walker, D. W. (2004). Lipid peroxidation, caspase-3 immunoreactivity, and pyknosis in late-gestation fetal sheep brain after umbilical cord occlusion. Pediatr. Res. 55, 864-871.

Castillo-Melendez, M., Yan, E., and Walker, D. W. (2005). Expression of erythropoietin and its receptor in the brain of late-gestation fetal sheep, and responses to asphyxia caused by umbilical cord occlusion. Dev. Neurosci. 27, 220-227.

Chang, L. W., Liu, J., Li, W. B., and Zhu, W. Z. (2007). Value of magnetic resonance imaging in the early evaluation of prognosis for hypoxicischemic encephalopathy in fullterm infants. Zhongguo Dang Dai Er Ke Za Zhi 9, 407-410.

Chang, Y. S., Mu, D., Wendland, M., Sheldon, R. A., Vexler, Z. S.,
McQuillen, P. S., et al. (2005). Erythropoietin improves functional and histological outcome in neonatal stroke. Pediatr. Res. 58, 106-111.

Charonis, A. S., Tsilibary, E. C. Yurchenco, P. D., and Furthmayr, H. (1985). Binding of laminin to type IV collagen: a morphological study. J. Cell Biol. 100, 1848-1853.

Chavez, J. C., Baranova, O., Lin, J., and Pichiule, P. (2006). The transcriptional activator hypoxia inducible factor 2 (HIF-2/EPAS-1) regulates the oxygen-dependent expression of erythropoietin in cortical astrocytes. J. Neurosci. 26, 9471-9481.

Chen, J., Zacharek, A., Zhang, C. Jiang, H., Li, Y., Roberts, C., et al. (2005). Endothelial nitric oxide synthase regulates brain-derived neurotrophic factor expression and neurogenesis after stroke in mice. J. Neurosci. 25, 2366-2375.

Chen, W., Jadhav, V., Tang, J., and Zhang, J. H. (2008). HIF-1alpha inhibition ameliorates neonatal brain injury in a rat pup hypoxicischemic model. Neurobiol. Dis. 31, 433-441.

Cobbs, C. S., Chen, J., Greenberg, D. A., and Graham, S. H. (1998). Vascular endothelial growth factor expression in transient focal cerebral ischemia in the rat. Neurosci. Lett. 249, 79-82.

Coomber, B. L., and Stewart, P. A (1984). Morphometric analysis of CNS microvascular endothelium. Microvasc. Res. 30, 99-115.

Cornford, E. M., and Cornford, M. E. (1986). Nutrient transport and the blood-brain barrier in developing animals. Fed. Proc. 45, 2065-2072.

Cowan, F., Rutherford, M., Groenendaal, F., Eken, P., Mercuri, E., Bydder, G. M., et al. (2003). Origin and timing of brain lesions in term infants with neonatal encephalopathy. Lancet 361, 736-742.

Daneman, R., Zhou, L., Kebede, A. A., and Barres, B. A. (2010). Pericytes are required for blood-brain barrier integrity during embryogenesis. Nature 468, 562-566.

Dehouck, M. P., Vigne, P., Torpier, G., Breittmayer, J. P., Cecchelli, R., and Frelin, C. (1997). Endothelin-1 as a mediator of endothelial cellpericyte interactions in bovine brain capillaries. J. Cereb. Blood Flow Metab. 17, 464-469.

De Reuck, J. (1971). The human periventricular arterial blood supply and the anatomy of cerebral infarctions. Eur. Neurol. 5, 321-334.

de Vries, L. S., Groenendaal, F., Eken, P., Van Haastert, I. C., Rademaker,
K. J., and Meiners, L. C. (1997). Infarcts in the vascular distribution of the middle cerebral artery in preterm and fullterm infants. Neuropediatrics 28, 88-96.

del Zoppo, G. J., and Mabuchi, T. (2003). Cerebral microvessel responses to focal ischemia. J. Cereb. Blood Flow Metab. 23, 879-894.

Dimberg, A., Rolny, C., Van Meeteren, L., and Claesson-Welsh, L. (2010). "Vascular endothelial growth factors and receptors: signaling in vascular development," in Handbook of Cell Signalling, 2nd Edn, eds R. Bradshaw and E. Dennis (San Diego, CA: Academic Press), 1927-1937.

Dore-Duffy, P. (2008). Pericytes: pluripotent cells of the blood brain barrier. Curr. Pharm. Des. 14, 1581-1593.

Dore-Duffy, P., Katychev, A., Wang, X., and Van Buren, E. (2006). CNS microvascular pericytes exhibit multipotential stem cell activity J. Cereb. Blood Flow Metab. 26, 613-624.

Duz, B., Oztas, E., Erginay, T., Erdogan, E., and Gonul, E. (2007). The effect of moderate hypothermia in acute ischemic stroke on pericyte migration: an ultrastructural study. Cryobiology 55, 279-284.

Dvorak, H. F., Brown, L. F., Detmar, M., and Dvorak, A. M. (1995). Vascular permeability factor/vascular endothelial growth factor, microvascular hyperpermeability, and angiogenesis. Am. J. Pathol. 146, 1029-1039.

Ek, C. J., Dziegielewska, K. M., Habgood, M. D., and Saunders, N. R. (2012). Barriers in the developing brain and Neurotoxicology. Neurotoxicology 33, 586-604.

Ek, C. J., Dziegielewska, K. M., Stolp, H., and Saunders, N. R. (2006). Functional effectiveness of the blood-brain barrier to small watersoluble molecules in developing and adult opossum (Monodelphis domestica). J. Comp. Neurol. 496, 13-26.

Ek, C. J., Habgood, M. D., Dziegielewska, K. M., and Saunders, N. R. (2003). Structural characteristics and barrier properties of the choroid plexuses in developing brain of the opossum (Monodelphis Domestica). J. Comp. Neurol. 460, 451-464.

Ek, C. J., Wong, A., Liddelow, S. A., Johansson, P. A., Dziegielewska, K. M., and Saunders, N. R. (2010). Efflux mechanisms at the developing brain barriers: ABC-transporters in the fetal and postnatal rat. Toxicol. Lett. 197, 51-59. 
El-Khoury, N., Braun, A., Hu, F., Pandey, M., Nedergaard, M., Lagamma, E. F., et al. (2006). Astrocyte end-feet in germinal matrix, cerebral cortex, and white matter in developing infants. Pediatr. Res. 59, 673-679.

Elfont, R. M., Sundaresan, P. R., and Sladek, C. D. (1989). Adrenergic receptors on cerebral microvessels: pericyte contribution. Am. J. Physiol. 256, R224-R230.

Engelhardt, B. (2003). Development of the blood-brain barrier. Cell Tissue Res. 314, 119-129.

Estan, J., and Hope, P. (1997). Unilateral neonatal cerebral infarction in full term infants. Arch. Dis. Child. Fetal Neonatal Ed. 76, F88-F93.

Fan, X., Heijnen, C. J., Van Der Kooij, M. A., Groenendaal, F., and Van Bel, F. (2009). The role and regulation of hypoxia-inducible factor-1alpha expression in brain development and neonatal hypoxic-ischemic brain injury. Brain Res. Rev. 62, 99-108.

Feng, Y., Rhodes, P. G., and Bhatt, A. J. (2008). Neuroprotective effects of vascular endothelial growth factor following hypoxic ischemic brain injury in neonatal rats. Pediatr. Res. 64, 370-374

Feng, Y., Rhodes, P. G., and Bhatt, A. J. (2011). Dexamethasone pretreatment protects brain against hypoxic-ischemic injury partially through up-regulation of vascular endothelial growth factor A in neonatal rats. Neuroscience 179, 223-232.

Ferrari, D. C., Nesic, O., and PerezPolo, J. R. (2010a). Perspectives on neonatal hypoxia/ischemia-induced edema formation. Neurochem. Res. 35, 1957-1965.

Ferrari, D. C., Nesic, O. B., and Perez-Polo, J. R. (2010b). Oxygen resuscitation does not ameliorate neonatal hypoxia/ischemia-induced cerebral edema. J. Neurosci. Res. 88, 2056-2065.

Ferriero, D. M., Holtzman, D. M., Black, S. M., and Sheldon, R. A. (1996). Neonatal mice lacking neuronal nitric oxide synthase are less vulnerable to hypoxicischemic injury. Neurobiol. Dis. 3, 64-71.

Fischer, S., Wobben, M., Marti, H. H., Renz, D., and Schaper, W. (2002). Hypoxia-induced hyperpermeability in brain microvessel endothelial cells involves VEGF-mediated changes in the expression of zonula occludens-1. Microvasc. Res. 63, 70-80.
Fleiss, B., and Gressens, P. (2012). Tertiary mechanisms of brain damage: a new hope for treatment of cerebral palsy? Lancet Neurol. 11, 556-566.

Forsythe, J. A., Jiang, B. H., Iyer, N. V., Agani, F., Leung, S. W., Koos, R. D., et al. (1996). Activation of vascular endothelial growth factor gene transcription by hypoxia-inducible factor 1. Mol. Cell. Biol. 16, 4604-4613.

Fossan, G., Cavanagh, M. E., Evans, C. A., Malinowska, D. H., Mollgard, K., Reynolds, M. L., et al. (1985). CSFbrain permeability in the immature sheep fetus: a CSF-brain barrier. Brain Res. 350, 113-124.

Fujimoto, E., Miki, A., and Mizoguti, H. (1989). Histochemical study of the differentiation of microglial cells in the developing human cerebral hemispheres. J. Anat. 166, 253-264.

Fujinaga, H., Baker, C. D., Ryan, S. L., Markham, N. E., Seedorf, G. J., Balasubramaniam, V., et al. (2009). Hyperoxia disrupts vascular endothelial growth factor-nitric oxide signaling and decreases growth of endothelial colonyforming cells from preterm infants. Am. J. Physiol. Lung Cell. Mol. Physiol. 297, L1160-L1169.

Furuse, M., Hirase, T., Itoh, M., Nagafuchi, A., Yonemura, S., and Tsukita, S. (1993). Occludin: a novel integral membrane protein localizing at tight junctions. J. Cell Biol. 123, 1777-1788.

Furuse, M., Sasaki, H., and Tsukita, S. (1999). Manner of interaction of heterogeneous claudin species within and between tight junction strands. J. Cell Biol. 147, 891-903.

Gale, N. W., Thurston, G., Hackett, S. F., Renard, R., Wang, Q., McClain, J., et al. (2002). Angiopoietin-2 is required for postnatal angiogenesis and lymphatic patterning, and only the latter role is rescued by Angiopoietin-1. Dev. Cell 3, 411-423.

George, E. L., Georges-Labouesse, E. N., Patel-King, R. S., Rayburn, H., and Hynes, R. O. (1993). Defects in mesoderm, neural tube and vascular development in mouse embryos lacking fibronectin. Development 119, 1079-1091.

Glass, H. C., Glidden, D., Jeremy, R. J., Barkovich, A. J., Ferriero, D. M., and Miller, S. P. (2009). Clinical neonatal seizures are independently associated with outcome in infants at risk for hypoxic-ischemic brain injury. J. Pediatr. 155, 318-323.

Goldstein, G. W. (1988). Endothelial cell-astrocyte interactions. A cellular model of the blood-brain barrier. Ann. N.Y. Acad. Sci. 529, 31-39.
Gonul, E., Duz, B., Kahraman, S., Kayali, H., Kubar, A., and Timurkaynak, E. (2002). Early pericyte response to brain hypoxia in cats: an ultrastructural study. Microvasc. Res. 64, 116-119.

Gonzalez, F. F., McQuillen, P., Mu, D. Chang, Y., Wendland, M., Vexler, Z., et al. (2007). Erythropoietin enhances long-term neuroprotection and neurogenesis in neonatal stroke. Dev. Neurosci. 29, 321-330.

Gora-Kupilas, K., and Josko, J. (2005). The neuroprotective function of vascular endothelial growth factor (VEGF). Folia Neuropathol. 43 , 31-39.

Gould, S. J., and Howard, S. (1988). An immunocytochemical study of the germinal layer vasculature in the developing fetal brain using Ulex europaeus 1 lectin. J. Pathol. 156, 129-135.

Gussin, H. A., Bischoff, F. Z., Hoffman, R., and Elias, S. (2002). Endothelial precursor cells in the peripheral blood of pregnant women. J. Soc. Gynecol. Investig. 9, 357-361.

Hagberg, H., Mallard, C., Rousset, C. I., and Xiaoyang, W. (2009). Apoptotic mechanisms in the immature brain: involvement of mitochondria. $J$. Child Neurol. 24, 1141-1146.

Hamann, G. F., Liebetrau, M., Martens, H., Burggraf, D., Kloss, C. U., Bultemeier, G., et al. (2002). Microvascular basal lamina injury after experimental focal cerebral ischemia and reperfusion in the rat. J. Cereb. Blood Flow Metab. 22, 526-533.

Hamann, G. F., Okada, Y., and del Zoppo, G. J. (1996). Hemorrhagic transformation and microvascular integrity during focal cerebral ischemia/reperfusion. J. Cereb. Blood Flow Metab. 16, 1373-1378.

Hamann, G. F., Okada, Y., Fitridge, R., and del Zoppo, G. J. (1995). Microvascular basal lamina antigens disappear during cerebral ischemia and reperfusion. Stroke 26 , 2120-2126.

Hamilton, N. B., Attwell, D., and Hall, C. N. (2010). Pericytemediated regulation of capillary diameter: a component of neurovascular coupling in health and disease. Front. Neuroenerg. 2:5. doi: 10.3389/fnene.2010.00005

Hamm, S., Dehouck, B., Kraus, J., Wolburg-Buchholz, K., Wolburg, H., Risau, W., et al. (2004). Astrocyte mediated modulation of blood-brain barrier permeability does not correlate with a loss of tight junction proteins from the cellular contacts. Cell Tissue Res. $315,157-166$
Hamrick, S. E., and Ferriero, D. M. (2003). The injury response in the term newborn brain: can we neuroprotect? Curr. Opin. Neurol. 16, 147-154.

Hansen, T. M., Moss, A. J., and Brindle, N. P. (2008). Vascular endothelial growth factor and angiopoietins in neurovascular regeneration and protection following stroke. Curr. Neurovasc. Res. 5, 236-245.

Hermann, D. M., and Zechariah, A. (2009). Implications of vascular endothelial growth factor for postischemic neurovascular remodeling. J. Cereb. Blood Flow Metab. 29, 1620-1643.

Hippenstiel, S., Krull, M., Ikemann, A., Risau, W., Clauss, M., and Suttorp, N. (1998). VEGF induces hyperpermeability by a direct action on endothelial cells. Am. J. Physiol. 274, L678-L684.

Hirase, T., Staddon, J. M., Saitou, M., Ando-Akatsuka, Y., Itoh, M., Furuse, M., et al. (1997). Occludin as a possible determinant of tight junction permeability in endothelial cells. J. Cell Sci. 110(Pt 14), 1603-1613.

Hirschi, K. K., and D'Amore, P. A. (1996). Pericytes in the microvasculature. Cardiovasc. Res. 32, 687-698.

Hoeben, A., Landuyt, B., Highley, M. S., Wildiers, H., Van Oosterom, A. T., and De Bruijn, E. A. (2004). Vascular endothelial growth factor and angiogenesis. Pharmacol. Rev. 56, 549-580.

Holash, J., Maisonpierre, P. C. Compton, D., Boland, P., Alexander, C. R., Zagzag, D., et al. (1999). Vessel cooption, regression, and growth in tumors mediated by angiopoietins and VEGF. Science 284, 1994-1998.

Huang, Z., Huang, P. L., Ma, J., Meng, W., Ayata, C., Fishman, M. C., et al. (1996). Enlarged infarcts in endothelial nitric oxide synthase knockout mice are attenuated by nitro-L-arginine. J. Cereb. Blood Flow Metab. 16, 981-987.

Hutchins, K. D., Dickson, D. W., Rashbaum, W. K., and Lyman, W. D. (1992). Localization of microglia in the human fetal cervical spinal cord. Brain Res. Dev. Brain Res. 66, 270-273.

Ikeda, T., Murata, Y., Quilligan, E. J., Parer, J. T., Doi, S., and Park, S. D. (1998). Brain lipid peroxidation and antioxidant levels in fetal lambs 72 hours after asphyxia by partial umbilical cord occlusion. Am. J. Obstet. Gynecol. 178, 474-478.

Ikonomidou, C., and Kaindl, A. M. (2011). Neuronal death and oxidative stress in the developing 
brain. Antioxid. Redox Signal. 14, 1535-1550.

Inder, T. E., and Volpe, J. J. (2000). Mechanisms of perinatal brain injury. Semin. Neonatol. 5, 3-16.

Iwai, M., Cao, G., Yin, W., Stetler, R. A., Liu, J., and Chen, J. (2007). Erythropoietin promotes neuronal replacement through revascularization and neurogenesis after neonatal hypoxia/ischemia in rats. Stroke 38, 2795-2803.

Iyer, N. V., Kotch, L. E., Agani, F., Leung, S. W., Laughner, E., Wenger, R. H., et al. (1998). Cellular and developmental control of $\mathrm{O} 2$ homeostasis by hypoxia-inducible factor 1 alpha. Genes Dev. 12, 149-162.

Jakobsson, L., Domogatskaya, A., Tryggvason, K., Edgar, D., and Claesson-Welsh, L. (2008). Laminin deposition is dispensable for vasculogenesis but regulates blood vessel diameter independent of flow. FASEB J. 22, 1530-1539.

Javed, M. J., Mead, L. E., Prater, D., Bessler, W. K., Foster, D., Case, J., et al. (2008). Endothelial colony forming cells and mesenchymal stem cells are enriched at different gestational ages in human umbilical cord blood. Pediatr. Res. 64, 68-73.

Jensen, A., Garnier, Y., and Berger, R. (1999). Dynamics of fetal circulatory responses to hypoxia and asphyxia. Eur. J. Obstet. Gynecol. Reprod. Biol. 84, 155-172.

Jensen, F. E., Wang, C., Stafstrom, C. E., Liu, Z., Geary, C., and Stevens, M. C. (1998). Acute and chronic increases in excitability in rat hippocampal slices after perinatal hypoxia in vivo. J. Neurophysiol. 79, 73-81.

Kamei, A., Houdou, S., Mito, T., Konomi, H., and Takashima, S. (1992). Developmental change in type VI collagen in human cerebral vessels. Pediatr. Neurol. 8, 183-186.

Kaur, C., Dheen, S. T., and Ling, E. A. (2007). From blood to brain: amoeboid microglial cell, a nascent macrophage and its functions in developing brain. Acta Pharmacol. Sin. 28, 1087-1096.

Kaur, C., and Ling, E. A. (2008). Blood brain barrier in hypoxic-ischemic conditions. Curr. Neurovasc. Res. 5, 71-81.

Kaur, C., and Ling, E. A. (2009). Periventricular white matter damage in the hypoxic neonatal brain: role of microglial cells. Prog. Neurobiol. 87, 264-280.

Kaur, C., Sivakumar, V., Ang, L. S., and Sundaresan, A. (2006a). Hypoxic damage to the periventricular white matter in neonatal brain: role of vascular endothelial growth factor, nitric oxide and excitotoxicity. $J$. Neurochem. 98, 1200-1216.

Kaur, C., Sivakumar, V., Zhang, Y., and Ling, E. A. (2006b). Hypoxiainduced astrocytic reaction and increased vascular permeability in the rat cerebellum. Glia 54, 826-839.

Kaya, D., Gursoy-Ozdemir, Y., Yemisci, M., Tuncer, N., Aktan, S., and Dalkara, T. (2005). VEGF protects brain against focal ischemia without increasing blood-brain permeability when administered intracerebroventricularly. J. Cereb. Blood Flow Metab. 25, 1111-1118.

Keck, P. J., Hauser, S. D., Krivi, G., Sanzo, K., Warren, T., Feder, J., et al. (1989). Vascular permeability factor, an endothelial cell mitogen related to PDGF. Science 246, 1309-1312.

Keogh, C. L., Yu, S. P., and Wei, L. (2007). The effect of recombinant human erythropoietin on neurovasculature repair after focal ischemic stroke in neonatal rats. J. Pharmacol. Exp. Ther. 322, 521-528.

Keunen, H., Blanco, C. E., Van Reempts, J. L., and Hasaart, T. H. (1997). Absence of neuronal damage after umbilical cord occlusion of 1015 , and 20 minutes in midgestation fetal sheep. Am. J. Obstet. Gynecol. 176, 515-520.

Kim, H., Lee, J. M., Park, J. S., Jo, S. A., Kim, Y. O., Kim, C. W., et al. (2008). Dexamethasone coordinately regulates angiopoietin-1 and VEGF: a mechanism of glucocorticoidinduced stabilization of blood-brain barrier. Biochem. Biophys. Res. Commun. 372, 243-248.

Kim, K. J., Li, B., Winer, J., Armanini, M., Gillett, N., Phillips, H. S., et al. (1993). Inhibition of vascular endothelial growth factor-induced angiogenesis suppresses tumour growth in vivo. Nature 362, 841-844.

Klatzo, I. (1987). Pathophysiological aspects of brain edema. Acta Neuropathol. 72, 236-239.

Kniesel, U., Risau, W., and Wolburg, H. (1996). Development of bloodbrain barrier tight junctions in the rat cortex. Brain Res. Dev. Brain Res. 96, 229-240.

Koelfen, W., Freund, M., and Varnholt, V. (1995). Neonatal stroke involving the middle cerebral artery in term infants: clinical presentation, EEG and imaging studies, and outcome. Dev. Med. Child Neurol. 37, 204-212.

Korzhevskii, D. E., and Otellin, V. A. (2000). Initial stage of vascular bed development in telencephalon of human embryo. Bull. Exp. Biol. Med. 129, 508-510.

Krupinski, J., Kaluza, J., Kumar, P., Kumar, S., and Wang, J. M. (1994). Role of angiogenesis in patients with cerebral ischemic stroke. Stroke 25 1794-1798.

Kumar, A., Mittal, R., Khanna, H. D. and Basu, S. (2008). Free radical injury and blood-brain barrier permeability in hypoxic-ischemic encephalopathy. Pediatrics 122 e722-e727.

Kuroiwa, T., Cahn, R., Juhler, M., Goping, G., Campbell, G., and Klatzo, I. (1985). Role of extracellular proteins in the dynamics of vasogenic brain edema. Acta Neuropathol. 66, 3-11.

Lagercrantz, J., Farnebo, F., Larsson, C. Tvrdik, T., Weber, G., and Piehl, F. (1998). A comparative study of the expression patterns for vegf, vegf$\mathrm{b} / \mathrm{vrf}$ and vegf-c in the developing and adult mouse. Biochim. Biophys. Acta 1398, 157-163.

Laurie, G. W., Leblond, C. P., Cournil, I., and Martin, G. R. (1980). Immunohistochemical evidence for the intracellular formation of basement membrane collagen (type IV) in developing tissues. J. Histochem. Cytochem. 28, 1267-1274.

Lee, J., Croen, L. A., Lindan, C., Nash, K. B., Yoshida, C. K., Ferriero, D. M., et al. (2005). Predictors of outcome in perinatal arterial stroke: a population-based study. Ann. Neurol. 58, 303-308.

Lenn, N. J., and Whitmore, L. (1985). Gestational changes in the germinal matrix of the normal rhesus monkey fetus. Pediatr. Res. 19, 130-135.

Lennmyr, F., Ata, K. A., Funa, K. Olsson, Y., and Terent, A. (1998). Expression of vascular endothelial growth factor (VEGF) and its receptors (Flt-1 and Flk-1) following permanent and transient occlusion of the middle cerebral artery in the rat. J. Neuropathol. Exp. Neurol. 57 , 874-882.

Leonardo, C. C., and Pennypacker, K. R. (2009). Neuroinflammation and MMPs: potential therapeutic targets in neonatal hypoxic-ischemic injury. J. Neuroinflammation 6, 13.

Leung, D. W., Cachianes, G., Kuang, W. J., Goeddel, D. V., and Ferrara, N. (1989). Vascular endothelial growth factor is a secreted angiogenic mitogen. Science 246, 1306-1309.

Li, A. M., Chau, V., Poskitt, K. J., Sargent, M. A., Lupton, B. A., Hill, A., et al. (2009). White matter injury in term newborns with neonatal encephalopathy. Pediatr. Res. 65, 85-89.
Li, C., and Jackson, R. M. (2002). Reactive species mechanisms of cellular hypoxia-reoxygenation injury. Am. J. Physiol. Cell Physiol. 282, C227-C241.

Liesi, P. (1985). Do neurons in the vertebrate CNS migrate on laminin? EMBO J. 4, 1163-1170.

Liesi, P., Kaakkola, S., Dahl, D., and Vaheri, A. (1984). Laminin is induced in astrocytes of adult brain by injury. EMBO J. 3, 683-686.

Liggins, G. C., and Howie, R. N. (1972). A controlled trial of antepartum glucocorticoid treatment for prevention of the respiratory distress syndrome in premature infants. Pediatrics 50, 515-525.

Lin, T. N., Nian, G. M., Chen, S. F., Cheung, W. M., Chang, C., Lin, W. C., et al. (2001). Induction of Tie-1 and Tie-2 receptor protein expression after cerebral ischemiareperfusion. J. Cereb. Blood Flow Metab. 21, 690-701.

Lin, T. N., Wang, C. K., Cheung, W. M., and Hsu, C. Y. (2000). Induction of angiopoietin and Tie receptor mRNA expression after cerebral ischemia-reperfusion. J. Cereb. Blood Flow Metab. 20, 387-395.

Ling, E. A., and Wong, W. C. (1993). The origin and nature of ramified and amoeboid microglia: a historical review and current concepts. Glia 7, 9-18.

Low, J. A. (2004). Determining the contribution of asphyxia to brain damage in the neonate. J. Obstet. Gynaecol. Res. 30, 276-286.

Low, J. A., Robertson, D. M., and Simpson, L. L. (1989). Temporal relationships of neuropathologic conditions caused by perinatal asphyxia. Am. J. Obstet. Gynecol. 160, 608-614.

Lukes, A., Mun-Bryce, S., Lukes, M., and Rosenberg, G. A. (1999). Extracellular matrix degradation by metalloproteinases and central nervous system diseases. Mol. Neurobiol. 19, 267-284.

Lynch, J. K., Hirtz, D. G., Deveber, G. and Nelson, K. B. (2002). Report of the national institute of neurological disorders and stroke workshop on perinatal and childhood stroke. Pediatrics 109, 116-123.

Maisonpierre, P. C., Suri, C., Jones, P. F., Bartunkova, S., Wiegand, S. J., Radziejewski, C., et al. (1997). Angiopoietin-2, a natural antagonist for Tie2 that disrupts in vivo angiogenesis. Science 277, 55-60.

Malaeb, S. N., Sadowska, G. B., and Stonestreet, B. S. (2007). Effects of maternal treatment with corticosteroids on tight junction protein expression in the cerebral cortex of 
the ovine fetus with and without exposure to in utero brain ischemia. Brain Res. 1160, 11-19.

Mallard, E. C., Williams, C. E., Johnston, B. M., and Gluckman, P. D. (1994). Increased vulnerability to neuronal damage after umbilical cord occlusion in fetal sheep with advancing gestation. Am. J. Obstet. Gynecol. 170, 206-214.

Marti, H. H. (2004). Erythropoietin and the hypoxic brain. J. Exp. Biol. 207, 3233-3242.

Marti, H. H., and Risau, W. (1998). Systemic hypoxia changes the organ-specific distribution of vascular endothelial growth factor and its receptors. Proc. Natl. Acad. Sci. U.S.A. 95, 15809-15814.

Marti, H. J., Bernaudin, M., Bellail, A., Schoch, H., Euler, M., Petit, E., et al. (2000). Hypoxia-induced vascular endothelial growth factor expression precedes neovascularization after cerebral ischemia. Am. J. Pathol. 156, 965-976.

Martin-Padura, I., Lostaglio, S., Schneemann, M., Williams, L., Romano, M., Fruscella, P., et al. (1998). Junctional adhesion molecule, a novel member of the immunoglobulin superfamily that distributes at intercellular junctions and modulates monocyte transmigration. J. Cell Biol. 142, 117-127.

Mayhan, W. G. (1999). VEGF increases permeability of the blood-brain barrier via a nitric oxide synthase/cGMP-dependent pathway. Am. J. Physiol. 276, C1148-C1153.

McClure, M. M., Riddle, A., Manese, M., Luo, N. L., Rorvik, D. A., Kelly, K. A., et al. (2008). Cerebral blood flow heterogeneity in preterm sheep: lack of physiologic support for vascular boundary zones in fetal cerebral white matter. J. Cereb. Blood Flow Metab. 28, 995-1008.

McLean, C., and Ferriero, D. (2004). Mechanisms of hypoxic-ischemic injury in the term infant. Semin. Perinatol. 28, 425-432.

Ment, L. R., Stewart, W. B., Ardito, T. A., and Madri, J. A. (1991). Beagle pup germinal matrix maturation studies. Stroke 22, 390-395.

Ment, L. R., Stewart, W. B., Fronc, R., Seashore, C., Mahooti, S., Scaramuzzino, D., et al. (1997). Vascular endothelial growth factor mediates reactive angiogenesis in the postnatal developing brain. Brain Res. Dev. Brain Res. 100, 52-61.

Miller, S. L., Wallace, E. M., and Walker, D. W. (2012). Antioxidant therapies: a potential role in perinatal medicine. Neuroendocrinology 96, 13-23.

Milner, R., and Campbell, I. L. (2002). Developmental regulation of betal integrins during angiogenesis in the central nervous system. Mol. Cell. Neurosci. 20, 616-626.

Milner, R., Hung, S., Erokwu, B., Dore-Duffy, P., Lamanna, J. C., and del Zoppo, G. J. (2008). Increased expression of fibronectin and the alpha 5 beta 1 integrin in angiogenic cerebral blood vessels of mice subject to hypobaric hypoxia. Mol. Cell. Neurosci. 38, 43-52.

Mishra, O. P., and DelivoriaPapadopoulos, M. (1999). Cellular mechanisms of hypoxic injury in the developing brain. Brain Res. Bull. 48, 233-238.

Mito, T., Konomi, H., Houdou, S., and Takashima, S. (1991). Immunohistochemical study of the vasculature in the developing brain. Pediatr. Neurol. 7, 18-22.

Miyawaki, T., Matsui, K., and Takashima, S. (1998). Developmental characteristics of vessel density in the human fetal and infant brains. Early Hum. Dev. 53, 65-72.

Morita-Fujimura, Y., Fujimura, M., Yoshimoto, T., and Chan, P. H (2001). Superoxide during reperfusion contributes to caspase- 8 expression and apoptosis after transient focal stroke. Stroke 32, 2356-2361.

Mu, D., Jiang, X., Sheldon, R. A., Fox, C. K., Hamrick, S. E., Vexler, Z. S., et al. (2003). Regulation of hypoxia-inducible factor lalpha and induction of vascular endothelial growth factor in a rat neonatal stroke model. Neurobiol. Dis. 14, 524-534.

Muramatsu, K., Fukuda, A., Togari, H., Wada, Y., and Nishino, H. (1997). Vulnerability to cerebral hypoxicischemic insult in neonatal but not in adult rats is in parallel with disruption of the blood-brain barrier. Stroke 28, 2281-2288. discussion 2288-2289.

Murohara, T., Horowitz, J. R., Silver, M., Tsurumi, Y., Chen, D., Sullivan, A., et al. (1998). Vascular endothelial growth factor/vascular permeability factor enhances vascular permeability via nitric oxide and prostacyclin. Circulation 97, 99-107.

Nag, S., Takahashi, J. L., and Kilty, D. W. (1997). Role of vascular endothelial growth factor in blood-brain barrier breakdown and angiogenesis in brain trauma. J. Neuropathol. Exp. Neurol. 56, 912-921.
Nakagawa, S., Deli, M. A., Nakao, S., Honda, M., Hayashi, K., Nakaoke, R., et al. (2007). Pericytes from brain microvessels strengthen the barrier integrity in primary cultures of rat brain endothelial cells. Cell. Mol. Neurobiol. 27, 687-694.

Nedelcu, J., Klein, M. A., Aguzzi, A., Boesiger, P., and Martin, E. (1999). Biphasic edema after hypoxicischemic brain injury in neonatal rats reflects early neuronal and late glial damage. Pediatr. Res. 46, 297-304.

O'Brien, J. S., and Sampson, E. L. (1965). Lipid composition of the normal human brain: gray matter, white matter, and myelin. J. Lipid Res. 6, 537-544.

Ogunshola, O. O., Stewart, W. B., Mihalcik, V., Solli, T., Madri, J. A., and Ment, L. R. (2000). Neuronal VEGF expression correlates with angiogenesis in postnatal developing rat brain. Brain Res. Dev. Brain Res. 119, 139-153.

Ohta, T., Kikuta, K., Imamura, H., Takagi, Y., Nishimura, M., Arakawa, Y., et al. (2006). Administration of ex vivo-expanded bone marrowderived endothelial progenitor cells attenuates focal cerebral ischemia-reperfusion injury in rats. Neurosurgery 59, 679-686. discussion: 679-686.

Otrock, Z. K., Mahfouz, R. A. Makarem, J. A., and Shamseddine, A. I. (2007). Understanding the biology of angiogenesis: review of the most important molecular mechanisms. Blood Cells Mol. Dis. 39, 212-220.

Paravicini, T. M., Drummond, G. R., and Sobey, C. G. (2004). Reactive oxygen species in the cerebral circulation: physiological roles and therapeutic implications for hypertension and stroke. Drugs 64 2143-2157.

Parer, J. T. (1998). Effects of fetal asphyxia on brain cell structure and function: limits of tolerance. Comp. Biochem. Physiol. A Mol. Integr. Physiol. 119, 711-716.

Peichev, M., Naiyer, A. J., Pereira, D., Zhu, Z., Lane, W. J., Williams, M., et al. (2000). Expression of VEGFR2 and AC133 by circulating human CD34(+) cells identifies a population of functional endothelial precursors. Blood 95, 952-958.

Perlman, J. M. (1998). Antenatal glucocorticoid, magnesium exposure, and the prevention of brain injury of prematurity. Semin. Pediatr. Neurol. 5, 202-210.

Perlman, J. M. (2004). Brain injury in the term infant. Semin. Perinatol. 28, 415-424.
Pichiule, P., and LaManna, J. C. (2002). Angiopoietin-2 and rat brain capillary remodeling during adaptation and deadaptation to prolonged mild hypoxia. J. Appl. Physiol. 93, 1131-1139.

Plate, K. H., Beck, H., Danner, S., Allegrini, P. R., and Wiessner, C. (1999). Cell type specific upregulation of vascular endothelial growth factor in an MCA-occlusion model of cerebral infarct. $J$. Neuropathol. Exp. Neurol. 58, 654-666.

Poschl, E., Schlotzer-Schrehardt, U. Brachvogel, B., Saito, K., Ninomiya, Y., and Mayer, U. (2004). Collagen IV is essential for basement membrane stability but dispensable for initiation of its assembly during early development. Development 131, 1619-1628.

Povlishock, J. T., Martinez, A. J., and Moossy, J. (1977). The fine structure of blood vessels of the telencephalic germinal matrix in the human fetus. Am. J. Anat. 149, 439-452.

Pryds, O., Greisen, G., Lou, H., and Friis-Hansen, B. (1989). Heterogeneity of cerebral vasoreactivity in preterm infants supported by mechanical ventilation. J. Pediatr. 115, 638-645.

Ramaswamy, V., Miller, S. P., Barkovich, A. J., Partridge, J. C., and Ferriero, D. M. (2004). Perinatal stroke in term infants with neonatal encephalopathy. Neurology 62, 2088-2091.

Ramsauer, M., Krause, D., and Dermietzel, R. (2002). Angiogenesis of the blood-brain barrier in vitro and the function of cerebral pericytes. FASEB J. 16, 1274-1276.

Risau, W. (1991). Induction of bloodbrain barrier endothelial cell differentiation. Ann. N.Y. Acad. Sci. 633, 405-419.

Risau, W. (1997). Mechanisms of angiogenesis. Nature 386, 671-674.

Risau, W., and Lemmon, V. (1988). Changes in the vascular extracellular matrix during embryonic vasculogenesis and angiogenesis. Dev. Biol. 125, 441-450.

Risau, W., Sariola, H., Zerwes, H. G., Sasse, J., Ekblom, P., Kemler, R., et al. (1988). Vasculogenesis and angiogenesis in embryonicstem-cell-derived embryoid bodies. Development 102, 471-478.

Risau, W., and Wolburg, H. (1990). Development of the blood-brain barrier. Trends Neurosci. 13 174-178.

Rosenstein, J. M., and Krum, J. M. (2004). New roles for VEGF in nervous tissue-beyond blood vessels. Exp. Neurol. 187, 246-253. 
Sadowska, G. B., Malaeb, S. N., and Stonestreet, B. S. (2010). Maternal glucocorticoid exposure alters tight junction protein expression in the brain of fetal sheep. Am. J. Physiol. Heart Circ. Physiol. 298, H179-H188.

Sanes, J. R., Engvall, E., Butkowski, R., and Hunter, D. D. (1990). Molecular heterogeneity of basal laminae: isoforms of laminin and collagen IV at the neuromuscular junction and elsewhere. J. Cell Biol. 111, 1685-1699.

Saunders, N. R., Ek, C. J., Habgood, M. D., and Dziegielewska, K. M. (2008). Barriers in the brain: a renaissance? Trends Neurosci. 31, 279-286.

Schmid-Brunclik, N., Burgi-Taboada, C., Antoniou, X., Gassmann, M., and Ogunshola, O. O. (2008). Astrocyte responses to injury: VEGF simultaneously modulates cell death and proliferation. Am. J. Physiol. Regul. Integr. Comp. Physiol. 295, R864-R873.

Schoch, H. J., Fischer, S., and Marti, H. H. (2002). Hypoxia-induced vascular endothelial growth factor expression causes vascular leakage in the brain. Brain 125, 2549-2557.

Scholler, K., Trinkl, A., Klopotowski, M., Thal, S. C., Plesnila, N., Trabold, R., et al. (2007). Characterization of microvascular basal lamina damage and blood-brain barrier dysfunction following subarachnoid hemorrhage in rats. Brain Res. 1142, 237-246.

Schulze, C., and Firth, J. A. (1993). Immunohistochemical localization of adherens junction components in blood-brain barrier microvessels of the rat. J. Cell Sci. 104(Pt 3), 773-782.

Semenza, G. L. (2009a). Regulation of oxygen homeostasis by hypoxiainducible factor 1. Physiology (Bethesda) 24, 97-106.

Semenza, G. L. (2009b). Vascular responses to hypoxia and ischemia. Arterioscler. Thromb. Vasc. Biol. 30, 648-652.

Sen, S., McDonald, S. P., Coates, P. T., and Bonder, C. S. (2011). Endothelial progenitor cells: novel biomarker and promising cell therapy for cardiovascular disease. Clin. Sci. (Lond.) 120, 263-283.

Sentilhes, L., Michel, C., Lecourtois, M., Catteau, J., Bourgeois, P., Laudenbach, V., et al. (2010). Vascular endothelial growth factor and its high-affinity receptor (VEGFR-2) are highly expressed in the human forebrain and cerebellum during development. $J$. Neuropathol. Exp. Neurol. 69, 111-128.
Shalak, L., and Perlman, J. M. (2004). Hypoxic-ischemic brain injury in the term infant-current concepts. Early Hum. Dev. 80, 125-141.

Shankaran, S., Bauer, C. R., Bain, R., Wright, L. L., and Zachary, J. (1995). Relationship between antenatal steroid administration and grades III and IV intracranial hemorrhage in low birth weight infants. The NICHD Neonatal Research Network. Am. J. Obstet. Gynecol. 173, 305-312.

Sheldon, R. A., Osredkar, D., Lee, C. L., Jiang, X., Mu, D., and Ferriero, D. M. (2009). HIF-1 alpha-deficient mice have increased brain injury after neonatal hypoxiaischemia. Dev. Neurosci. 31, 452-458.

Shimotake, J., Derugin, N., Wendland, M., Vexler, Z. S., and Ferriero, D. M. (2010). Vascular endothelial growth factor receptor-2 inhibition promotes cell death and limits endothelial cell proliferation in a neonatal rodent model of stroke. Stroke 41, 343-349.

Shweiki, D., Itin, A., Neufeld, G., GitayGoren, H., and Keshet, E. (1993). Patterns of expression of vascular endothelial growth factor (VEGF) and VEGF receptors in mice suggest a role in hormonally regulated angiogenesis. J. Clin. Invest. 91, 2235-2243.

Sims, M. E., Turkel, S. B., Halterman, G., and Paul, R. H. (1985). Brain injury and intrauterine death. Am. J. Obstet. Gynecol. 151, 721-723.

Skold, M. K., and Kanje, M. (2008) Vascular endothelial growth factor in central nervous system injuries - a vascular growth factor getting nervous? Curr. Neurovasc. Res. 5 , 246-259.

Skuli, N., Liu, L., Runge, A., Wang, T., Yuan, L., Patel, S., et al. (2009). Endothelial deletion of hypoxia-inducible factor-2alpha (HIF-2alpha) alters vascular function and tumor angiogenesis. Blood 114, 469-477.

Skuli, N., and Simon, M. C. (2009). HIF-1alpha versus HIF-2alpha in endothelial cells and vascular functions: is there a master in angiogenesis regulation? Cell Cycle 8, 3252-3253.

Sobrino, T., Hurtado, O., Moro, M. A., Rodriguez-Yanez, M., Castellanos, M., Brea, D., et al. (2007). The increase of circulating endothelial progenitor cells after acute ischemic stroke is associated with good outcome. Stroke 38, 2759-2764.

Stanley, F. J., and Watson, L. (1992). Trends in perinatal mortality and cerebral palsy in Western Australia, 1967 to 1985 . BMJ 304, 1658-1663.

Stephens, J. (1995). Cerebral palsy: the courts catch up with sad realities. Med. J. Aust. 162, 110.

Stevenson, B. R., Siliciano, J. D. Mooseker, M. S., and Goodenough, D. A. (1986). Identification of ZO-1, a high molecular weight polypeptide associated with the tight junction (zonula occludens) in a variety of epithelia. J. Cell Biol. 103 755-766.

Stonestreet, B. S., Burgess, G. H., and Cserr, H. F. (1992). Bloodbrain barrier integrity and brain water and electrolytes during hypoxia/hypercapnia and hypotension in newborn piglets. Brain Res. 590, 263-270.

Stonestreet, B. S., Patlak, C. S. Pettigrew, K. D., Reilly, C. B., and Cserr, H. F. (1996). Ontogeny of blood-brain barrier function in ovine fetuses, lambs, and adults. Am. J. Physiol. 271, R1594-R1601.

Stonestreet, B. S., Petersson, K. H., Sadowska, G. B., Pettigrew, K. D., and Patlak, C. S. (1999) Antenatal steroids decrease bloodbrain barrier permeability in the ovine fetus. Am. J. Physiol. 276, R283-R289.

Stonestreet, B. S., Sadowska, G. B. Leeman, J., Hanumara, R. C. Petersson, K. H., and Patlak, C. S (2006). Effects of acute hyperosmolality on blood-brain barrier function in ovine fetuses and lambs. Am. J. Physiol. Regul. Integr. Comp. Physiol. 291, R1031-R1039.

Sugawara, J., Mitsui-Saito, M. Hoshiai, T., Hayashi, C., Kimura, Y., and Okamura, K. (2005). Circulating endothelial progenitor cells during human pregnancy. J. Clin. Endocrinol. Metab. 90 1845-1848.

Sun, Y., Jin, K., Xie, L., Childs, J. Mao, X. O., Logvinova, A., et al. (2003). VEGF-induced neuroprotection, neurogenesis, and angiogenesis after focal cerebral ischemia. J. Clin. Invest. 111, 1843-1851.

Suri, C., Jones, P. F., Patan, S. Bartunkova, S., Maisonpierre, P. C., Davis, S., et al. (1996). Requisite role of angiopoietin-1, a ligand for the TIE2 receptor, during embryonic angiogenesis. Cell 87 1171-1180.

Svedin, P., Hagberg, H., Savman, K., Zhu, C., and Mallard, C. (2007). Matrix metalloproteinase9 gene knock-out protects the immature brain after cerebral hypoxia-ischemia. J. Neurosci. 27 1511-1518.
Swarte, R., Lequin, M., Cherian, P., Zecic, A., Van Goudoever, J., and Govaert, P. (2009). Imaging patterns of brain injury in termbirth asphyxia. Acta paediatr. 98, 586-592.

Taguchi, A., Matsuyama, T., Moriwaki, H., Hayashi, T., Hayashida, K., Nagatsuka, K., et al. (2004). Circulating CD34-positive cells provide an index of cerebrovascular function. Circulation 109, 2972-2975.

Takashima, S., Armstrong, D. L., and Becker, L. E. (1978). Subcortical leukomalacia. Relationship to development of the cerebral sulcus and its vascular supply. Arch. Neurol. 35, 470-472.

Takashima, S., and Tanaka, K. (1978a). Development of cerebrovascular architecture and its relationship to periventricular leukomalacia. Arch Neurol. 35, 11-16.

Takashima, S., and Tanaka, K. (1978b). Microangiography and vascular permeability of the subependymal matrix in the premature infant. Can. J. Neurol. Sci. 5, 45-50.

Takenouchi, T., Kasdorf, E., Engel, M., Grunebaum, A., and Perlman, J. M. (2012). Changing pattern of perinatal brain injury in term infants in recent years. Pediatr. Neurol. 46 , 106-110.

Tan, S., Zhou, F., Nielsen, V. G., Wang, Z., Gladson, C. L., and Parks, D. A. (1998). Sustained hypoxia-ischemia results in reactive nitrogen and oxygen species production and injury in the premature fetal rabbit brain J. Neuropathol. Exp. Neurol. 57, 544-553.

Temesvari, P., Hencz, P., Joo, F., Eck, E., Szerdahelyi, P., and Boda, D. (1984) Modulation of the blood-brain barrier permeability in neonatal cytotoxic brain edema: laboratory and morphological findings obtained on newborn piglets with experimental pneumothorax. Biol. Neonate 46, 198-208.

Thanabalasundaram, G., Pieper, C. Lischper, M., and Galla, H. J. (2010) Regulation of the blood-brain barrier integrity by pericytes via matrix metalloproteinases mediated activation of vascular endothelial growth factor in vitro. Brain Res. 1347 $1-10$.

Thurston, G., Rudge, J. S., Ioffe, E., Zhou, H., Ross, L., Croll, S. D., et al. (2000). Angiopoietin-1 protects the adult vasculature against plasma leakage. Nat. Med. 6, 460-463.

Thurston, G., Suri, C., Smith, K., McClain, J., Sato, T. N. Yancopoulos, G. D., et al. (1999) Leakage-resistant blood vessels in 
mice transgenically overexpressing angiopoietin-1. Science 286, 2511-2514.

Timpl, R., Rohde, H., Robey, P. G., Rennard, S. I., Foidart, J. M., and Martin, G. R. (1979). Laminina glycoprotein from basement membranes. J. Biol. Chem. 254, 9933-9937.

Tomanek, R. J., and Schatteman, G. C. (2000). Angiogenesis: new insights and therapeutic potential. Anat. Rec. 261, 126-135.

Trollmann, R., Amann, K., Schoof, E., Beinder, E., Wenzel, D., Rascher, W., et al. (2003). Hypoxia activates the human placental vascular endothelial growth factor system in vitro and in vivo: up-regulation of vascular endothelial growth factor in clinically relevant hypoxic ischemia in birth asphyxia. Am. J. Obstet. Gynecol. 188, 517-523.

Trollmann, R., and Gassmann, M. (2009). The role of hypoxiainducible transcription factors in the hypoxic neonatal brain. Brain Dev. 31, 503-509.

Trommer, B. L., Groothuis, D. R., and Pasternak, J. F. (1987). Quantitative analysis of cerebral vessels in the newborn puppy: the structure of germinal matrix vessels may predispose to hemorrhage. Pediatr. Res. 22, 23-28.

Truettner, J. S., Alonso, O. F., and Dalton Dietrich, W. (2005). Influence of therapeutic hypothermia on matrix metalloproteinase activity after traumatic brain injury in rats. J. Cereb. Blood Flow Metab. 25, 1505-1516.

Tu, Y. F., Tsai, Y. S., Wang, L. W., Wu, H. C., Huang, C. C., and Ho, C. J. (2011). Overweight worsens apoptosis, neuroinflammation and blood-brain barrier damage after hypoxic ischemia in neonatal brain through JNK hyperactivation. J. Neuroinflammation 8, 40.

Tuor, U. I., Simone, C., and Bascaramurty, S. (1992). Local blood-brain barrier in the newborn rabbit: postnatal changes in alpha-aminoisobutyric acid transfer within medulla, cortex, and selected brain areas. J. Neurochem. 59, 999-1007.

Valable, S., Bellail, A., Lesne, S., Liot, G., Mackenzie, E. T., Vivien, D., et al. (2003). Angiopoietin-1-induced PI3-kinase activation prevents neuronal apoptosis. FASEB J. 17, 443-445.

Valable, S., Montaner, J., Bellail, A., Berezowski, V., Brillault, J., Cecchelli, R., et al. (2005). VEGFinduced $\mathrm{BBB}$ permeability is associated with an MMP-9 activity increase in cerebral ischemia: both effects decreased by Ang-1. J. Cereb. Blood Flow Metab. 25, 1491-1504.

Van den Broeck, C., Himpens, E., Vanhaesebrouck, P., Calders, P. and Oostra, A. (2007). Influence of gestational age on the type of brain injury and neuromotor outcome in high-risk neonates. Eur. J. Pediatr. 167, 1005-1009.

Van den Tweel, E. R., Nijboer, C., Kavelaars, A., Heijnen, C. J., Groenendaal, F., and Van Bel, F. (2005). Expression of nitric oxide synthase isoforms and nitrotyrosine formation after hypoxia-ischemia in the neonatal rat brain. J. Neuroimmunol. 167, 64-71.

Vannucci, S. J., and Hagberg, H. (2004). Hypoxia-ischemia in the immature brain. J. Exp. Biol. 207, 3149-3154.

van Zwieten, E. J., Ravid, R., Swaab, D. F., and Van De Woude, T. (1988). Immunocytochemically stained vasopressin binding sites on blood vessels in the rat brain. Brain Res. 474, 369-373.

Vasiljevic, B., Maglajlic-Djukic, S., Gojnic, M., Stankovic, S., Ignjatovic, S., and Lutovac, D. (2011). New insights into the pathogenesis of perinatal hypoxic-ischemic brain injury. Pediatr. Int. 53, 454-462.

Veltkamp, R., Bieber, K., Wagner, S., Beynon, C., Siebing, D. A., Veltkamp, C., et al. (2006). Hyperbaric oxygen reduces basal lamina degradation after transient focal cerebral ischemia in rats. Brain Res. 1076, 231-237.

Vinukonda, G., Dummula, K., Malik, S., Hu, F., Thompson, C. I., Csiszar, A., et al. (2010). Effect of prenatal glucocorticoids on cerebral vasculature of the developing brain. Stroke 41, 1766-1773.

Virgintino, D., Errede, M., Robertson, D., Capobianco, C., Girolamo, F., Vimercati, A., et al. (2004). Immunolocalization of tight junction proteins in the adult and developing human brain. Histochem. Cell Biol. 122, 51-59.

Virgintino, D., Errede, M., Robertson, D., Girolamo, F., Masciandaro, A., and Bertossi, M. (2003). VEGF expression is developmentally regulated during human brain angiogenesis. Histochem. Cell Biol. 119, 227-232.

Volpe, J. J. (1989). Intraventricular hemorrhage and brain injury in the premature infant. Neuropathology and pathogenesis. Clin. Perinatol. 16, 361-386.

Volpe, J. J. (1998). Brain injury in the premature infant: overview of clinical aspects, neuropathology, and pathogenesis. Semin. Pediatr. Neurol. 5, 135-151.

Wagner, S., Tagaya, M., Koziol, J. A., Quaranta, V., and del Zoppo, G. J. (1997). Rapid disruption of an astrocyte interaction with the extracellular matrix mediated by integrin alpha 6 beta 4 during focal cerebral ischemia/reperfusion. Stroke 28, 858-865.

Wang, J., and Milner, R. (2006). Fibronectin promotes brain capillary endothelial cell survival and proliferation through alpha5betal and alphavbeta3 integrins via MAP kinase signalling. J. Neurochem. 96, 148-159.

Wang, W., Dentler, W. L., and Borchardt, R. T. (2001). VEGF increases BMEC monolayer permeability by affecting occludin expression and tight junction assembly. Am. J. Physiol. Heart Circ. Physiol. 280, H434-H440.

Wiener, C. M., Booth, G., and Semenza, G. L. (1996). In vivo expression of mRNAs encoding hypoxia-inducible factor 1 . Biochem. Biophys. Res. Commun. 225, 485-488.

Wigglesworth, J. S., and Pape, K. E. (1978). An integrated model for haemorrhagic and ischaemic lesions in the newborn brain. Early Hum. Dev. 2, 179-199.

Willis, C. L., Leach, L., Clarke, G. J., Nolan, C. C., and Ray, D. E. (2004). Reversible disruption of tight junction complexes in the rat bloodbrain barrier, following transitory focal astrocyte loss. Glia 48, 1-13.

Witt, K. A., Mark, K. S., Hom, S., and Davis, T. P. (2003). Effects of hypoxia-reoxygenation on rat blood-brain barrier permeability and tight junctional protein expression. Am. J. Physiol. Heart Circ. Physiol. 285, H2820-H2831.

Wolff, J. R., Rajan, K. T., and Noack, W. (1974). The fate and fine structure of fragments of blood vessels in CNS tissue cultures. Cell Tissue Res. 156, 89-102.

Xie, Y. C., Li, C. Y., Li, T., Nie, D. Y., and Ye, F. (2007). Effect of mild hypothermia on angiogenesis in rats with focal cerebral ischemia. Neurosci. Lett. 422, 87-90.

$\mathrm{Xu}, \mathrm{H} ., \mathrm{Hu}, \mathrm{F}$, Sado, Y., Ninomiya, Y., Borza, D. B., Ungvari, Z., et al. (2008). Maturational changes in laminin, fibronectin, collagen IV, and perlecan in germinal matrix, cortex, and white matter and effect of betamethasone. J. Neurosci. Res. 86, 1482-1500.

Yamagishi, S., Yonekura, H., Yamamoto, Y., Fujimori, H.,
Sakurai, S., Tanaka, N., et al. (1999). Vascular endothelial growth factor acts as a pericyte mitogen under hypoxic conditions. Lab. Invest. 79, 501-509.

Yamaji, R., Okada, T., Moriya, M., Naito, M., Tsuruo, T., Miyatake, K., et al. (1996). Brain capillary endothelial cells express two forms of erythropoietin receptor mRNA. Eur. J. Biochem. 239, 494-500.

Yancopoulos, G. D., Davis, S., Gale, N. W., Rudge, J. S., Wiegand, S. J., and Holash, J. (2000). Vascular-specific growth factors and blood vessel formation. Nature 407, 242-248.

Yang, D., Nemkul, N., Shereen, A., Jone, A., Dunn, R. S., Lawrence, D. A., et al. (2009). Therapeutic administration of plasminogen activator inhibitor-1 prevents hypoxicischemic brain injury in newborns. J. Neurosci. 29, 8669-8674.

Yang, D., Sun, Y. Y., Nemkul, N., Baumann, J. M., Shereen, A., Dunn, R. S., et al. (2012). Plasminogen activator inhibitor-1 mitigates brain injury in a rat model of infection-sensitized neonatal hypoxia-ischemia. Cereb. Cortex. doi: 10.1093/cercor/bhs115. [Epub ahead of print].

Yenari, M. A., and Han, H. S. (2012). Neuroprotective mechanisms of hypothermia in brain ischaemia. Nat. Rev. Neurosci. 13, 267-278.

Yeo, E. J., Cho, Y. S., Kim, M. S., and Park, J. W. (2008). Contribution of HIF-1alpha or HIF-2alpha to erythropoietin expression: in vivo evidence based on chromatin immunoprecipitation. Ann. Hematol. 87, 11-17.

Young, P. P., Fantz, C. R., and Sands, M. S. (2004). VEGF disrupts the neonatal blood-brain barrier and increases life span after non-ablative BMT in a murine model of congenital neurodegeneration caused by a lysosomal enzyme deficiency. Exp. Neurol. 188, 104-114.

Yurchenco, P. D., and Schittny, J. C. (1990). Molecular architecture of basement membranes. FASEB J. 4, 1577-1590.

Zalewska, T., Ziemka-Nalecz, M., Sarnowska, A., and DomanskaJanik, K. (2002). Involvement of MMPs in delayed neuronal death after global ischemia. Acta Neurobiol. Exp. (Wars) 62, 53-61.

Zhang, Z. G., Zhang, L., Jiang, Q., and Chopp, M. (2002a). Bone marrowderived endothelial progenitor cells participate in cerebral neovascularization after focal cerebral ischemia in the adult mouse. Circ. Res. 90, 284-288. 
Zhang, Z. G., Zhang, L., Tsang, W., Soltanian-Zadeh, H., Morris, D., Zhang, R., et al. (2002b). Correlation of VEGF and angiopoietin expression with disruption of blood-brain barrier and angiogenesis after focal cerebral ischemia. J. Cereb. Blood Flow Metab. 22, 379-392.

Zhang, Z. G., Zhang, L., Jiang, Q., Zhang, R., Davies, K., Powers, C., et al. (2000). VEGF enhances angiogenesis and promotes blood-brain barrier leakage in the ischemic brain. J. Clin. Invest. 106, 829-838.

Zhu, Y., Lee, C., Shen, F., Du, R., Young, W. L., and Yang, G. Y. (2005). Angiopoietin-2 facilitates vascular endothelial growth factor-induced angiogenesis in the mature mouse brain. Stroke 36, 1533-1537.

Conflict of Interest Statement: The authors declare that the research was conducted in the absence of any commercial or financial relationships that could be construed as a potential conflict of interest.

Received: 15 August 2012; accepted: 17 October 2012; published online: 09 November 2012.

Citation: Baburamani AA, Ek CJ, Walker DW and Castillo-Melendez M (2012) Vulnerability of the developing brain to hypoxic-ischemic damage: contribution of the cerebral vasculature to injury and repair? Front. Physio. 3:424. doi: 10.3389/fphys.2012.00424
This article was submitted to Frontiers in Vascular Physiology, a specialty of Frontiers in Physiology.

Copyright (C) 2012 Baburamani, Ek, Walker and Castillo-Melendez. This is an open-access article distributed under the terms of the Creative Commons Attribution License, which permits use, distribution and reproduction in other forums, provided the original authors and source are credited and subject to any copyright notices concerning any third-party graphics etc. 